Maraveas, C., Wang, Y.C., Swailes, T. and Sotiriadis, G., An Experimental Investigation of Mechanical

Properties of Structural Cast Iron at Elevated Temperatures and after Cooling Down, Fire Safety Journal, Vol. 71, pp 340-352, January 2015. DOI: 10.1016/i.firesaf.2014.11.026

\title{
An Experimental Investigation of Mechanical Properties of Structural Cast Iron at Elevated Temperatures and after Cooling Down
}

Maraveas, C. ${ }^{1}$, Wang, Y.C. ${ }^{1 *}$, Swailes, T. ${ }^{1}$ and Sotiriadis, G. ${ }^{2}$

1. School of Mechanical, Aerospace and Civil Engineering, University of Manchester, UK

2. Applied Mechanics and Vibrations Lab, Dept. of Mechanical Engineering, University of Patras, Rio, Greece

* corresponding author: yong.wang@manchester.ac.uk, (44) 1613068968

\begin{abstract}
This paper presents the results of an extensive experimental investigation of the mechanical properties of structural cast iron at elevated temperatures and after cooling down to room temperature. A total of 135 tests were carried out. The specimens were subjected to tension ( 83 tests), compression (48 tests) or were heated for measurement of the thermal expansion ( 4 tests). The tests in tension include 35 steady-state tests up to $900^{\circ} \mathrm{C}, 32$ transient tests $\left(5^{\circ} \mathrm{C} / \mathrm{min}\right.$ and $20^{\circ} \mathrm{C} / \mathrm{min}$ heating rates, applied stress from 20 to $80 \%$ of $0,2 \%$ proof stress) and 16 tests after cooling down (heated up to $800^{\circ} \mathrm{C}$ and cooled down with two different methods: quenching and air flow cooling). 32 steadystate tests (up to $900^{\circ} \mathrm{C}$ ) and 16 transient tests $\left(5^{\circ} \mathrm{C} / \mathrm{min}\right.$ and $20^{\circ} \mathrm{C} / \mathrm{min}$ heating rates,
\end{abstract}


applied stress from 50 to $120 \%$ of $0,2 \%$ proof stress) were carried out for specimens in compression. The paper evaluates and proposes elevated temperatures material models.

Keywords: mechanical properties; cast iron; high temperatures; stress strain temperature relationship; thermal expansion; residual strength.

\section{Introduction}

From the middle of the $18^{\text {th }}$ until the beginning of the $20^{\text {th }}$ century [1], cast iron elements were commonly encountered in the structural framing of buildings in Great Britain, United States and Central and Northern Europe ([2] to [9]). However, since cast iron is no longer a mainstream construction material, there is a lack of extensive research on this type of construction. Furthermore, of the research investigations conducted on cast iron structures, most have been focused on their ambient temperature behaviour [10] -[14]. Although there have been some efforts of evaluating the behavior of cast iron structural members in fire conditions, such studies have either been based on early fire tests or largely qualitative observations of their response in fire incidents [15] - [23]. There was a general lack of rigour when evaluating fire performance of cast iron structures even when dealing with rehabilitation of the fire exposed cast iron construction [22], [23]. A main reason for the limited treatment of this subject is the lack of reliable data regarding the mechanical behavior of cast iron at elevated temperatures and after cooling down. The detailed survey of literature by the present authors [24] has revealed that there is a good number of historical sources of data on various aspects of mechanical properties of cast iron at elevated temperatures [25], [26], [27], [28]. However, there is a large scatter in results from these different sources. Also, these earlier references often lack detailed 
information on the experimental methodology as well as composition of the cast iron investigated. To enable accurate assessment of the fire resistance of cast iron structures and their residual structural performance after cooling down, it is clearly important that reliable mechanical property data is available. The follow-on sensitivity study by the present authors [29] has shown that the fire resistance of cast-iron structural members is particularly sensitive to the following mechanical properties: strength, thermal expansion and modulus of elasticity. Providing detailed experimental information on elevated temperature and residual mechanical properties of cast iron is the focus of this paper.

This paper presents the results of an extensive experimental programme involving a total of 135 cast iron specimens subjected to elevated temperature effects. Both steady-state and transient heating conditions were applied. Since cast iron has different tensile and compressive properties, the specimens were tested in tension and compression. Furthermore, a total of 16 specimens were tested to measure their residual strengths after cooling down from high temperatures. Two different cooling methods were used, one natural cooling and one quenching with cold water. Based on the test results, mathematical expressions have been proposed for the mechanical property - temperature relationships.

\section{Testing arrangement}

\subsection{Test specimens}

The test specimens were made from two cast iron columns with a circular hollow crosssection. These columns came from the Orangery at Tatton Park in Cheshire in the UK. 65 specimens with dimensions shown in Figure 1a were made from the first column 
(material 1, Table 1) and were prepared for tensile testing according to EN ISO 6892-1: 2009 [30]. The grip part of the specimens tested at room temperature were made into three specimens for thermal expansion testing. From the other column (material 2, Table 1), 17 specimens (with dimensions shown in Figure 1b) were prepared for tensile testing according to the same standard [30] and 49 specimens (with dimensions shown in Figure 1c and 1d) were prepared for compression testing according to the ASTM E9-09 [31] and ASTM E209-00 [32] standards. The chemical compositions of the materials are presented in Table 1. Figure 2 shows the typical microstructure of the test specimens, which clearly differs from that of a homogeneous material.

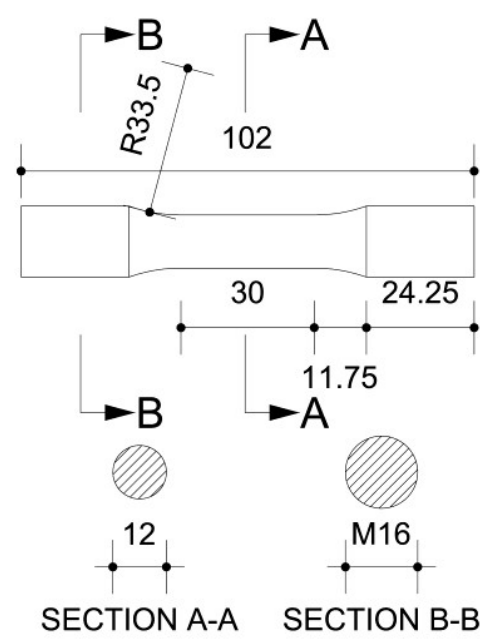

(a) tensile specimen (material 1)

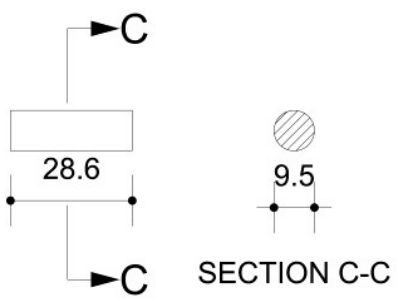

(c) compressive specimen (material 2) 

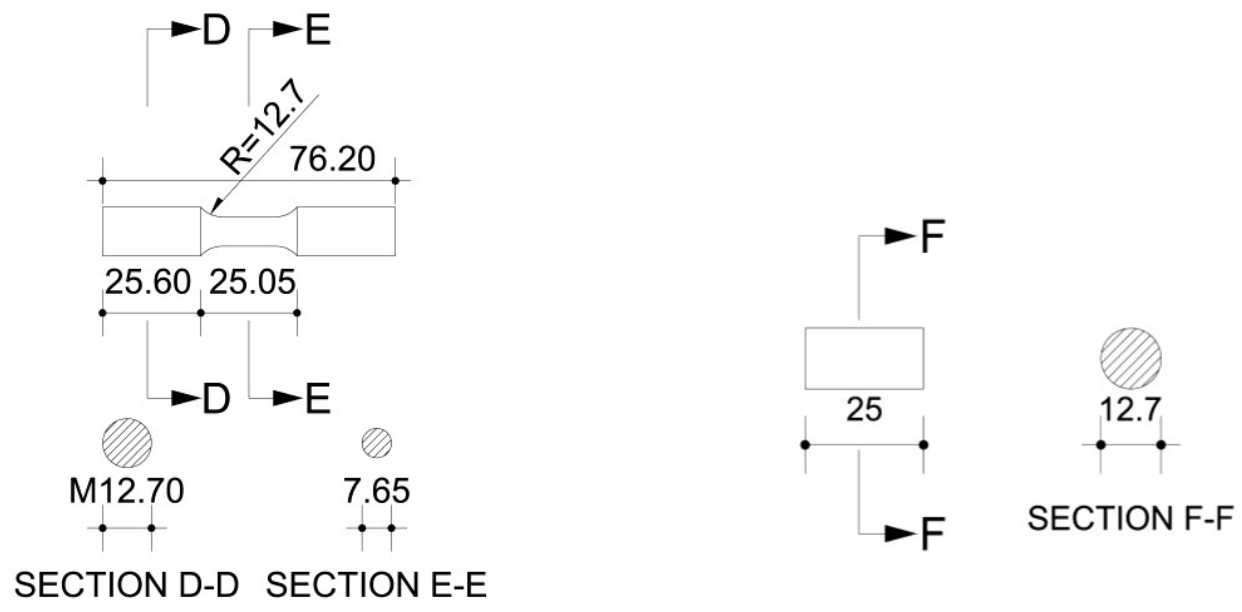

(b) tensile specimen (material 2)

(d)thick compressive specimen (material 1)

Figure 1: Cast iron specimens for tensile and compressive tests (units in $\mathrm{mm}$ ).

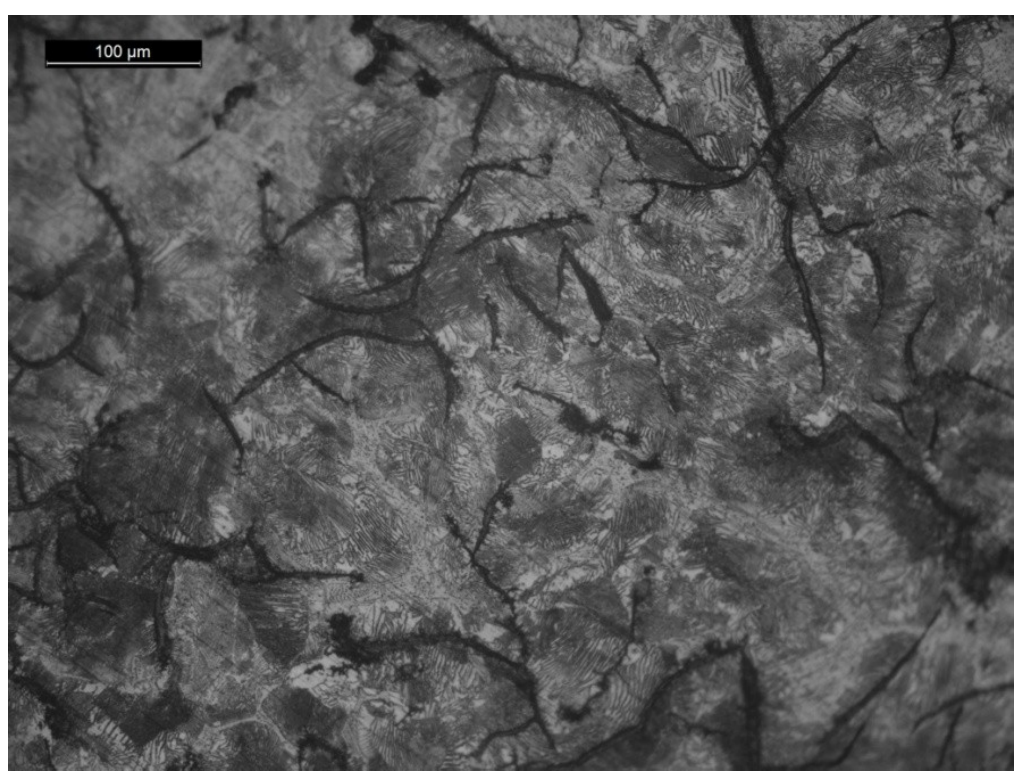




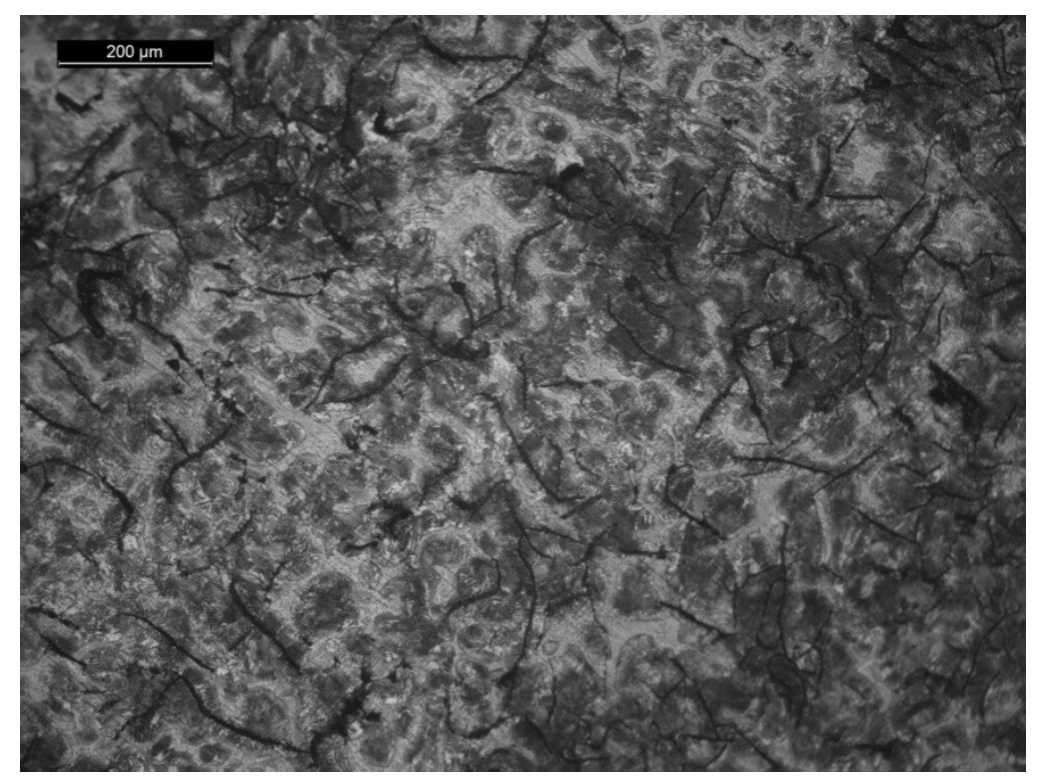

Figure 2: Microstructure of cast iron test specimens (200X (upper), 100X (lower))

Table 1: Chemical compositions of the cast iron test specimens

\begin{tabular}{cccccccccc}
\hline \multirow{2}{*}{ Material } & $\begin{array}{c}\mathrm{C} \\
(\%)\end{array}$ & $\begin{array}{c}\mathrm{Mn} \\
(\%)\end{array}$ & $\begin{array}{c}\mathrm{Si} \\
(\%)\end{array}$ & $\begin{array}{c}\mathrm{P} \\
(\%)\end{array}$ & $\begin{array}{c}\mathrm{S} \\
(\%)\end{array}$ & $\begin{array}{c}\mathrm{Ni} \\
(\%)\end{array}$ & $\begin{array}{c}\mathrm{Cr} \\
(\%)\end{array}$ & $\begin{array}{c}\mathrm{Mo} \\
(\%)\end{array}$ & $\begin{array}{c}\mathrm{Cu} \\
(\%)\end{array}$ \\
\hline 1 & $2.90 \sim 2.95$ & 0.36 & 1.41 & 0.65 & 0.21 & 0.02 & - & - & 0.02 \\
2 & 3.075 & 0.488 & 1.37 & 0.595 & 0.14 & - & - & - & - \\
\hline
\end{tabular}

\subsection{Testing device}

The testing devices include a type 8802 INSTRON Universal Testing Machine of $250 \mathrm{kN}$ maximum capacity, a type SC1706 short electric furnace with a maximum heating capability of $1400^{\circ} \mathrm{C}$, a spring-loaded type thermo-couple (placed on the specimen to measure the specimen temperature) and an Epsilon CP8830C (25mm/ $\pm 20 \%)$ high temperature extensometer. Figure 3 shows the experimental arrangement. 
(a)

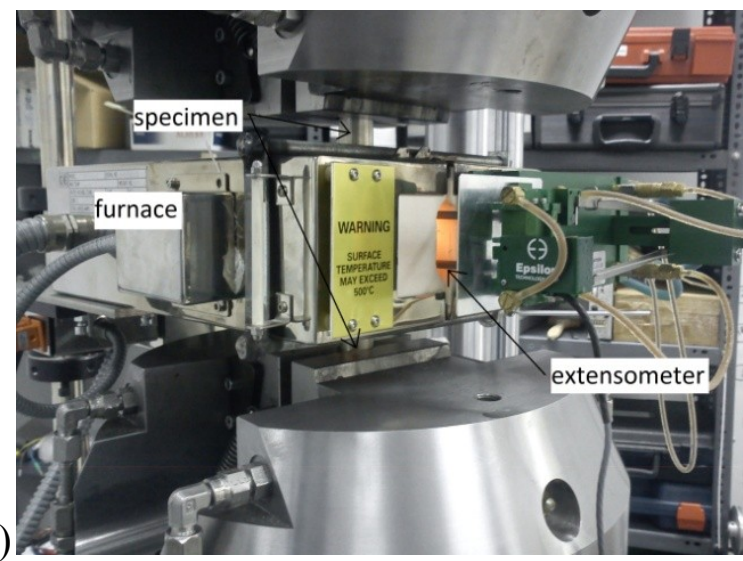

(b)
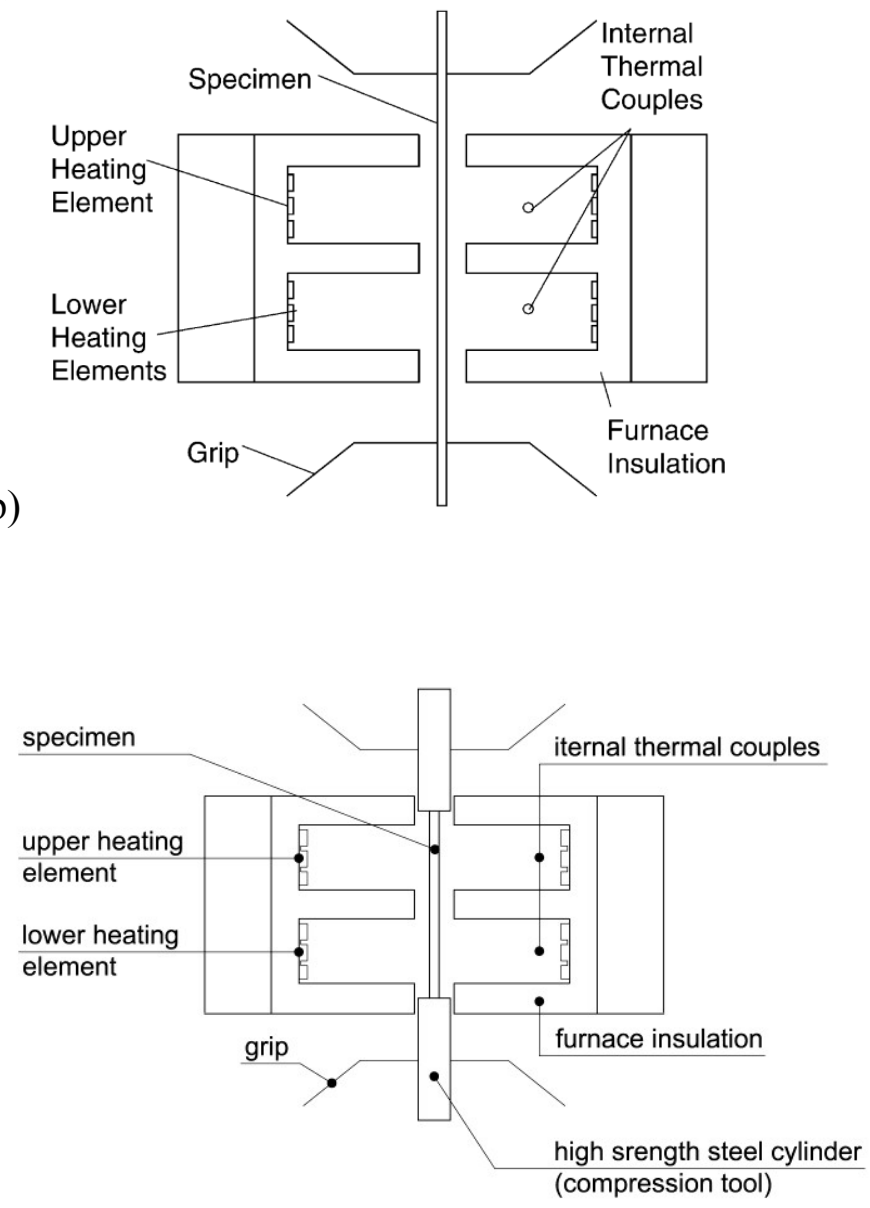

(c)

Figure 3: (a) High-temperature tensile and compressive testing device, (b) general arrangement of the tensile tests and (c) general arrangement of the compression tests 


\subsection{Test Procedure}

The tests were categorized in eight groups (A to $\mathrm{H}$ ) according to the heating method, the type of stress applied (tensile or compressive) and the testing condition (during heating or after cooling down). Table 2 provides details of the experimental programme. 
Table 2: Test program with details

\begin{tabular}{|c|c|c|c|c|c|c|c|c|c|c|}
\hline $\begin{array}{l}\text { Group } \\
\text { No. }\end{array}$ & $\begin{array}{l}\text { Specimen } \\
\text { type } \\
\text { (Fig. 1) } \\
\end{array}$ & $\begin{array}{l}\text { Material } \\
\text { (Table 1) }\end{array}$ & Type of test & $\begin{array}{l}\text { Heating } \\
\text { method }\end{array}$ & $\begin{array}{l}\text { Cooling } \\
\text { method }\end{array}$ & $\begin{array}{l}\text { Number of } \\
\text { Specimens }\end{array}$ & $\begin{array}{c}\text { Test } \\
\text { Temperatures }\end{array}$ & $\begin{array}{l}\text { Initial Stress } \\
\text { Level }\end{array}$ & $\begin{array}{c}\text { Heating } \\
\text { Rate }\end{array}$ & Strain Rate \\
\hline A & (a) & 1 & Tension & $\begin{array}{l}\text { Steady } \\
\text { state }\end{array}$ & - & 18 & $\begin{array}{c}20^{\circ} \mathrm{C}, 100^{\circ} \mathrm{C} \text { to } \\
800^{\circ} \mathrm{C} @ 100^{\circ} \mathrm{C} \\
\text { interval } \\
\end{array}$ & - & $5^{\circ} \mathrm{C} / \mathrm{min}$ & $0,5 \mathrm{~mm} / \mathrm{min}$ \\
\hline B & (a) & 1 & Tension & Transient & - & 32 & - & $\begin{array}{c}10 \% \text { to } 80 \% \\
@ \text { interval of } \\
10 \% \text { of } 0.2 \% \\
\text { proof stress } \\
(185 \mathrm{MPa})\end{array}$ & $\begin{array}{l}5^{\circ} \mathrm{C} / \mathrm{min} \\
20^{\circ} \mathrm{C} / \mathrm{min}\end{array}$ & - \\
\hline $\mathrm{C}$ & $\begin{array}{c}\text { Cube } \\
10 * 10 * 7 \\
(\mathrm{~mm}) \& \\
(\mathrm{c})\end{array}$ & 1 & $\begin{array}{l}\text { Thermal } \\
\text { Expansion }\end{array}$ & - & - & $3+1$ & $\begin{array}{c}100^{\circ} \mathrm{C} \text { to } 800^{\circ} \mathrm{C} \\
\text { @ } 100^{\circ} \mathrm{C}\end{array}$ & - & $10^{\circ} \mathrm{C} / \mathrm{min}$ & - \\
\hline D-1 & (a) & 1 & $\begin{array}{c}\text { Tension after } \\
\text { cooling } \\
\text { down }\end{array}$ & $\begin{array}{l}\text { Steady } \\
\text { state }\end{array}$ & $\begin{array}{c}\text { Water } \\
\text { quenching }\end{array}$ & 8 & $\begin{array}{c}100^{\circ} \mathrm{C} \text { to } 800^{\circ} \mathrm{C} \\
\text { @ } 100^{\circ} \mathrm{C}\end{array}$ & - & $5^{\circ} \mathrm{C} / \mathrm{min}$ & $0,5 \mathrm{~mm} / \mathrm{min}$ \\
\hline E & (b) & 2 & Tension & $\begin{array}{l}\text { Steady } \\
\text { state }\end{array}$ & - & 17 & $\begin{array}{l}20^{\circ} \mathrm{C}, 500^{\circ} \mathrm{C} \text { to } \\
1000^{\circ} \mathrm{C} @ 100^{\circ} \mathrm{C}\end{array}$ & - & $5^{\circ} \mathrm{C} / \mathrm{min}$ & $0,5 \mathrm{~mm} / \mathrm{min}$ \\
\hline $\mathrm{F}$ & (c) & 2 & Compression & $\begin{array}{c}\text { Steady } \\
\text { state }\end{array}$ & - & 30 & $\begin{array}{c}20^{\circ} \mathrm{C} \text { to } 900^{\circ} \mathrm{C} \\
\text { (a) } 100^{\circ} \mathrm{C} \\
\end{array}$ & & $5^{\circ} \mathrm{C} / \mathrm{min}$ & $0,5 \mathrm{~mm} / \mathrm{min}$ \\
\hline G & (c) & 2 & Compression & Transient & - & 16 & - & $\begin{array}{c}50 \%, 80 \%, \\
100 \%, 120 \% \\
\text { of } 0.2 \% \text { proof } \\
\text { stress } \\
(372,30 \mathrm{MPa})\end{array}$ & $\begin{array}{l}5^{\circ} \mathrm{C} / \mathrm{min} \\
20^{\circ} \mathrm{C} / \mathrm{min}\end{array}$ & - \\
\hline $\mathrm{H}$ & (d) & 1 & Compression & - & - & 2 & Ambient & - & - & $0,5 \mathrm{~mm} / \mathrm{min}$ \\
\hline
\end{tabular}




\section{Tensile mechanical properties of cast iron at elevated temperatures}

\subsection{General}

It is known [33] that cast iron does not exhibit a distinct yield stress point and that its stiffness in tension changes as the various flaws in its microstructure open [28],[34]. For this reason, a clear definition of the mechanical properties (i.e. yield stress, fracture stress etc) presented in this paper is given below. These are generally in accordance with references [25], [28], [33] pertaining to the experimental investigation of the mechanical properties of cast iron.

In Figure 4, a typical stress-strain diagram of cast iron in tension is presented. From this it can be observed that the initial tangent modulus, which is typically (in other materials) assumed to be equal to the Young's modulus of elasticity, does not follow the stressstrain diagram, except for the region in which the strain has small values. For this reason, the tensile elastic modulus in this paper is assumed to be equal to the secant modulus of elasticity at $0,2 \%$ proof stress. The yield strength is defined, conventionally, as the $0,2 \%$ proof stress based on using the initial tangent modulus. The proportional limit does not have to be defined, because, practically, there is no linear region in the stress-strain diagram. The ultimate tensile strength $f_{u}$ is defined as the maximum stress in the diagram and the fracture stress $\sigma_{\mathrm{f}}$ is the stress at the failure (breaking) point of the specimen. In general, $\mathrm{f}_{\mathrm{u}} / \sigma_{\mathrm{f}}=1$, but for temperatures higher than $500^{\circ} \mathrm{C}$ this ratio reduces below unity $\left(\mathrm{f}_{\mathrm{u}} / \sigma_{\mathrm{f}}<1\right)$. 


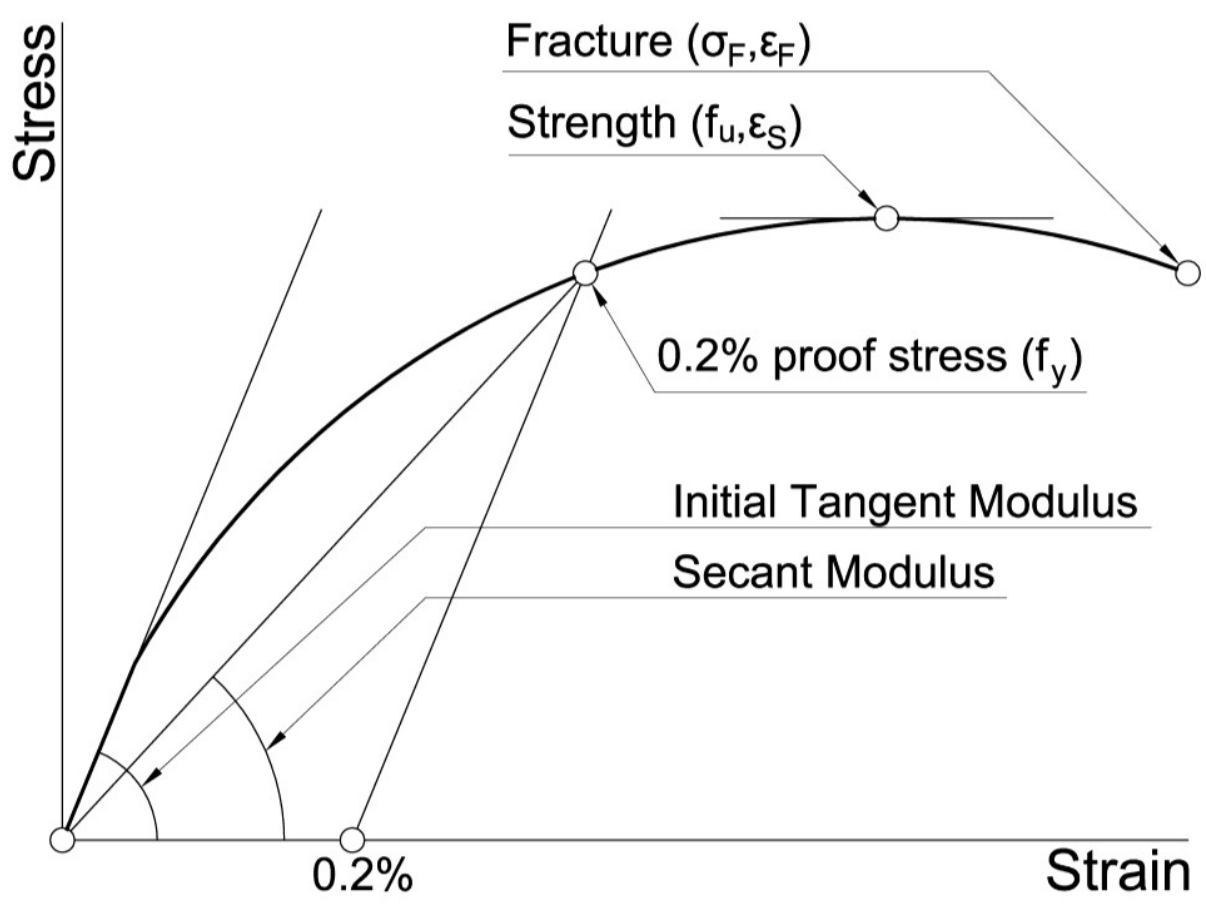

Figure 4: Typical stress-strain diagram of cast iron in tension

The observed failure mode in all specimens was brittle, intergranular, without necking around the failure region (Fig. 5a). At temperatures exceeding $700^{\circ} \mathrm{C}$, the fracture surface was less flat (Fig. 5b), which is an indication of a moderately brittle fracture. Some of the specimens tested at $700^{\circ} \mathrm{C}$ and $800^{\circ} \mathrm{C}$ failed through multiple surfaces (Fig. 5c), which suggests that the increased elongation of the specimens in the high temperature region may have led to a different failure mechanism, most possibly as a result of opening of the flaws. Because necking of the specimens is not observed, i.e. the cross-section is not altered, the engineering stress is identical with the true stress. During these tests, the behavior of the material when near failure in tension was unstable, with the results from the duplicate specimens at the same temperature showing some inconsistence. The duplicate specimens were made from the opposite sides of the same cast iron column. A 
chemical analysis of these specimens showed a $0.05 \%$ difference in the carbon content, which may have contributed to the difference in results.

The specimens from Group E, which were intended for testing at $1000^{\circ} \mathrm{C}$, failed at $950^{\circ} \mathrm{C}-965^{\circ} \mathrm{C}$ under a small prestress load of approximately $5 \mathrm{~N}$ (applied to stabilize the extensometer). The corresponding specimens in Group B displayed stable behavior at $1000^{\circ} \mathrm{C}$ when the applied load was low. A possible explanation for this is the small diameter of the specimens in Group E.

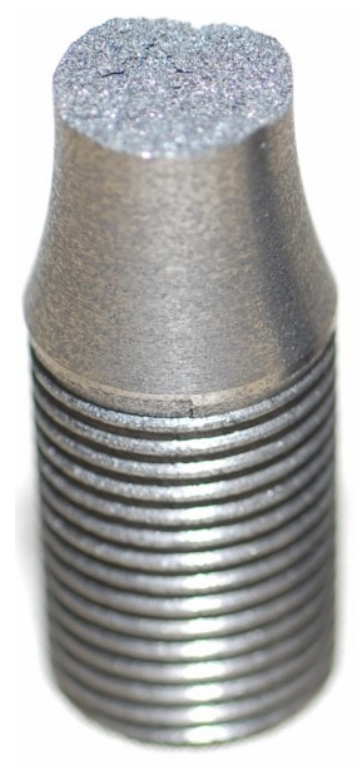

(a)

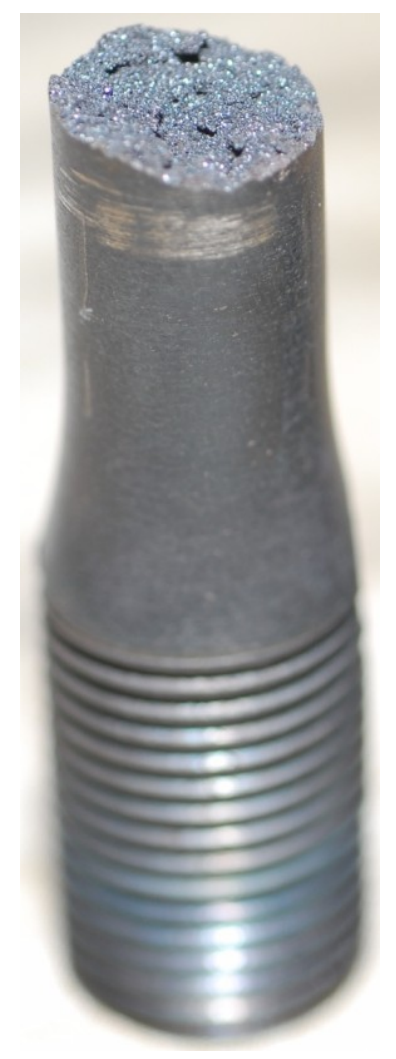

(b)

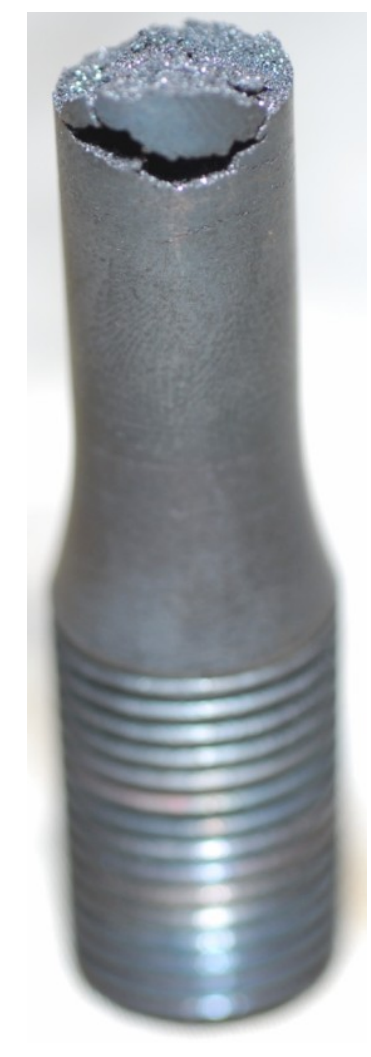

(c)

Figure 5: Different intergranular fracture modes in tension: (a) brittle failure at room temperature, (b) moderately brittle fracture at $700^{\circ} \mathrm{C}$ and (c) multi surface moderately brittle fracture at $700^{\circ} \mathrm{C}$. 


\subsection{Stress-strain curves in tension}

Figure 6 presents the recorded stress-strain curves from the steady state tests at different temperatures for group A and Group E specimens. As can be seen, the stress-strain curves were not influenced up to temperatures of $400^{\circ} \mathrm{C}$ and failure occurred at strains of about $0.5 \%$. The mechanical response of Material 1 (Table 1) remained unaffected even at $500^{\circ} \mathrm{C}$ (Figures $6 \mathrm{a}$ and $6 \mathrm{~b}$ ), whereas Material 2 at $500^{\circ} \mathrm{C}$ (Figure $6 \mathrm{c}$ ) failed at strain equal to $1,2 \%$, accompanied by a minor decrease in strength. For temperatures above $500^{\circ} \mathrm{C}$, ductile behaviour was observed with failure occurring at strains of $1.8 \%$ for $600^{\circ} \mathrm{C}$ and at $4 \%$ for higher temperatures (with the exception of Figure 6a, which shows an earlier failure for the corresponding specimen). It is worth noting that the stress-strain curves are nonlinear in the entire strain range.

Figure 7 show the temperature-strain relationships from the transient state tests for group B specimens. From such curves, the transient stress-strain curves were obtained following the procedure of [35]. Figure 8 shows typical comparison of stress-strain curves from the steady-state and transient state tests. The results show little difference between the steady state and the transient stress-strain diagrams, with the transient strengths being slightly higher than the steady state values. 
(a)

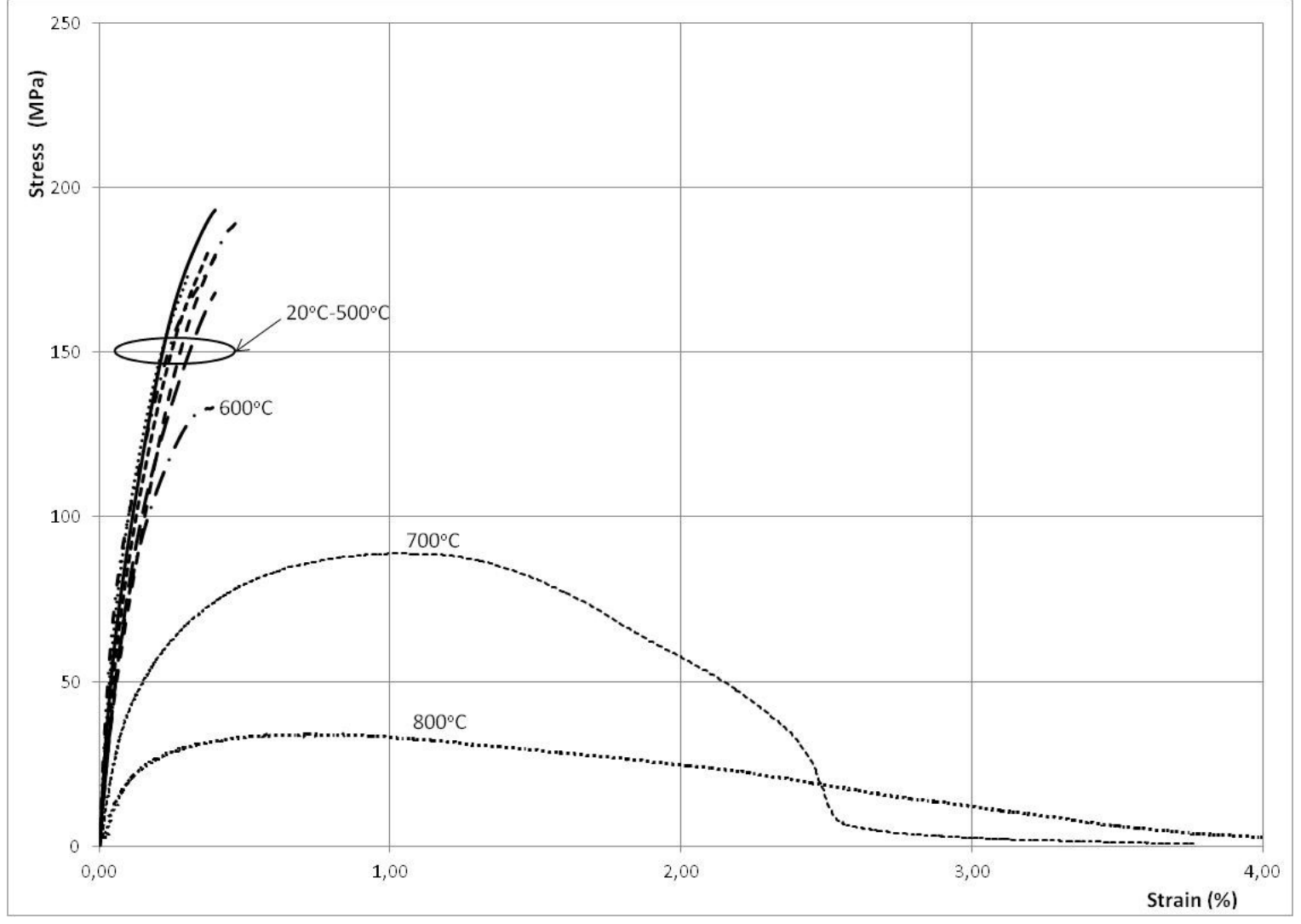

14 
(b)

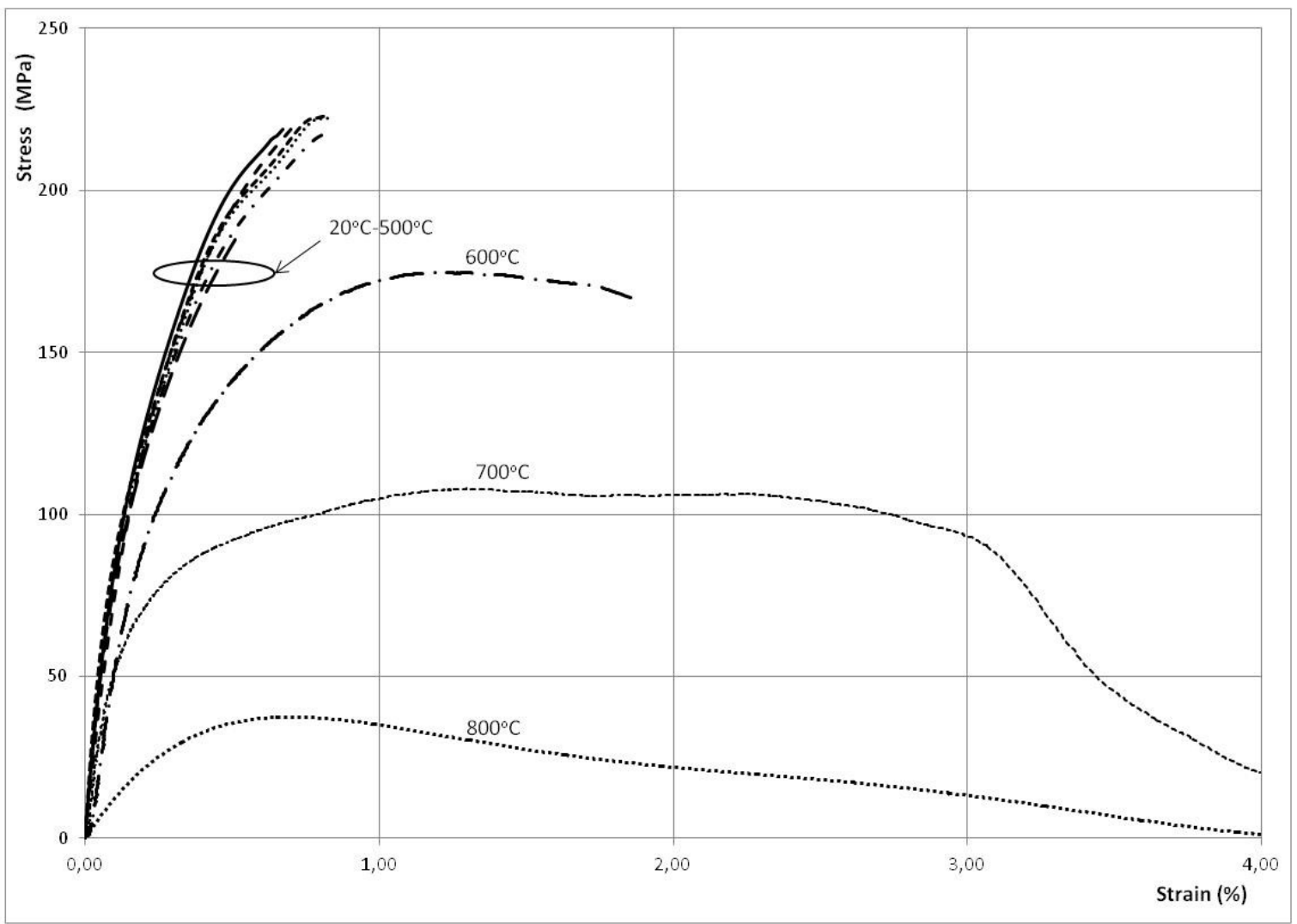


(c)

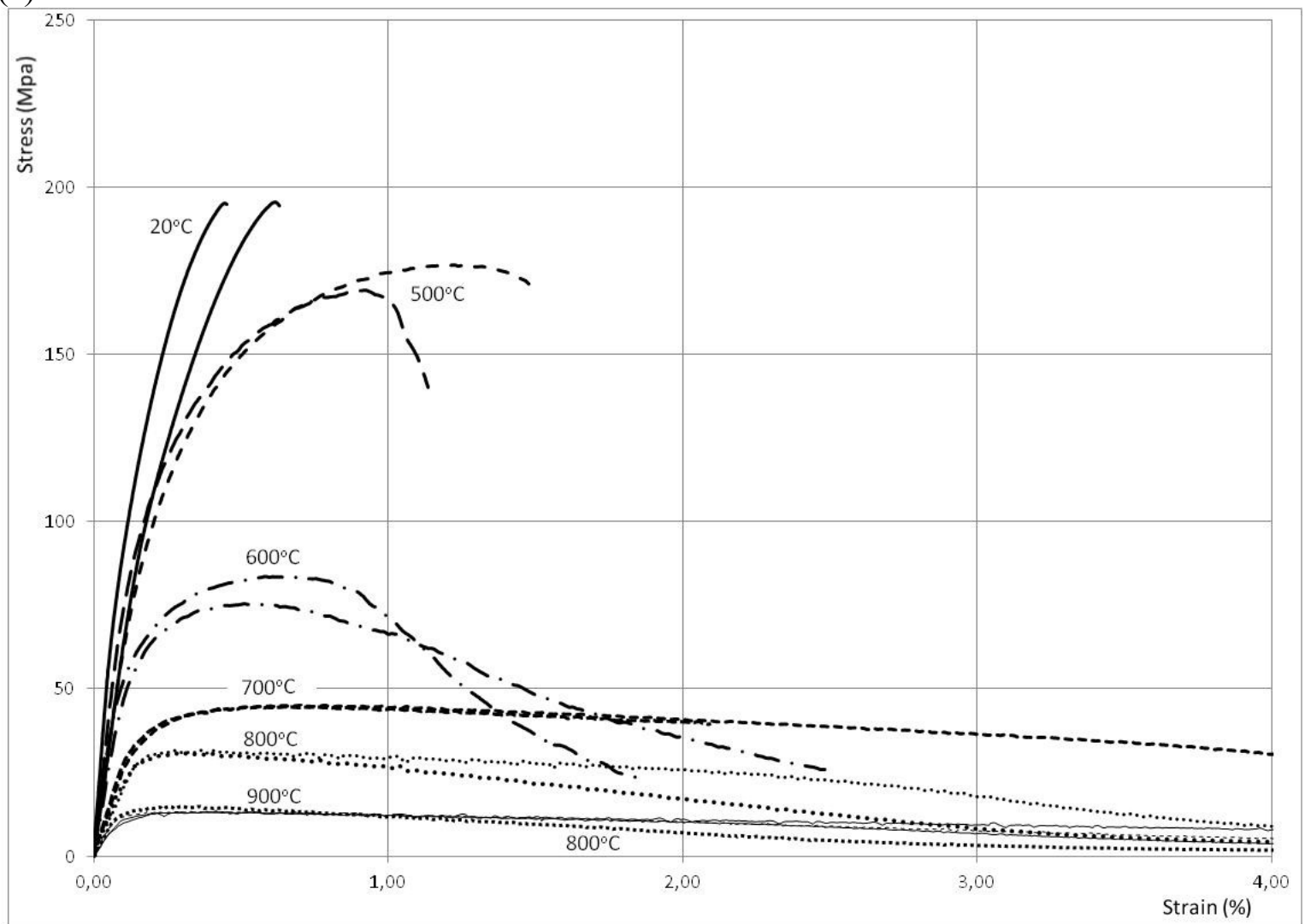

Figure 6: Steady state results under tension, (a) and (b) Group A tests, (c) Group E tests. 
(a)

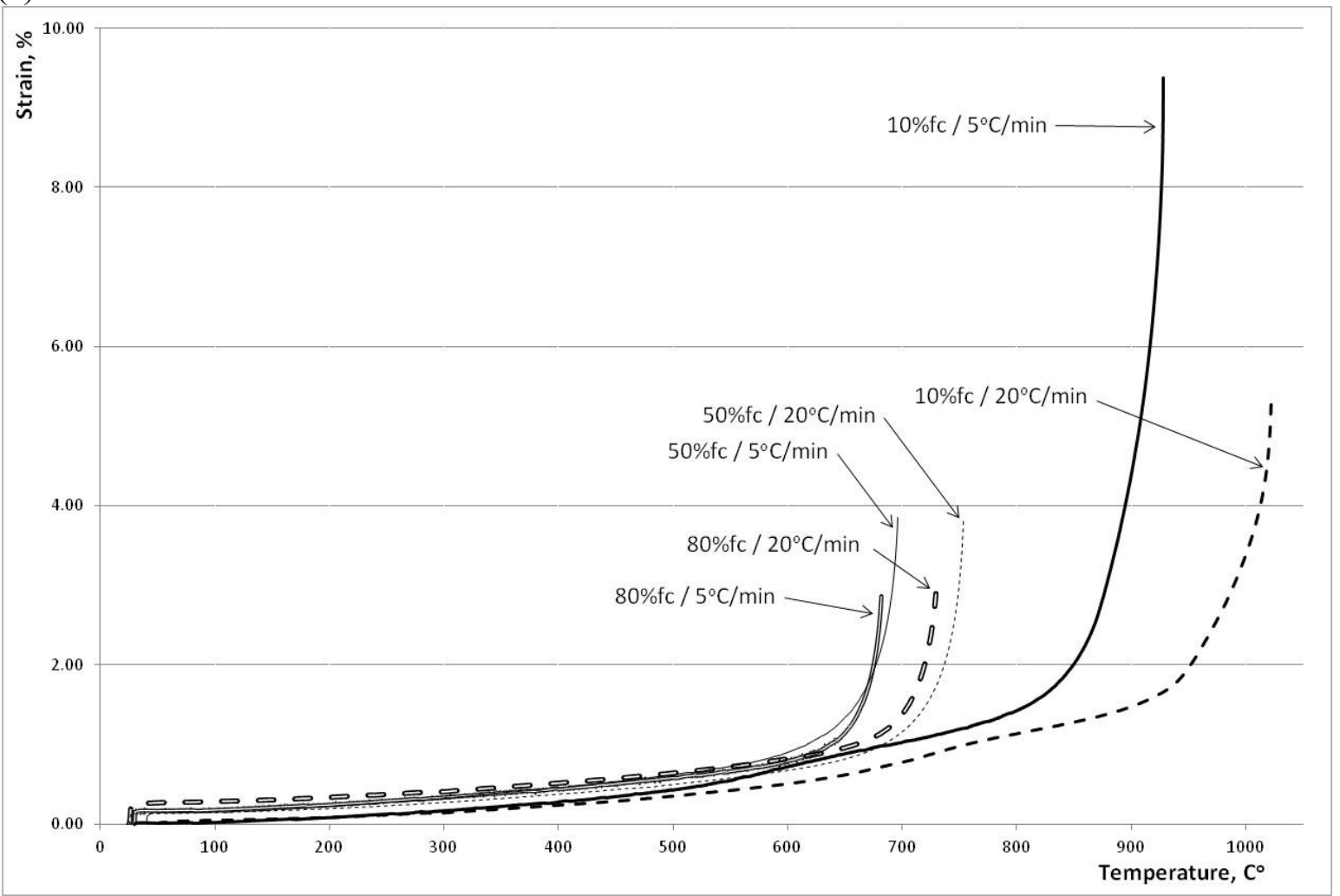

(b)

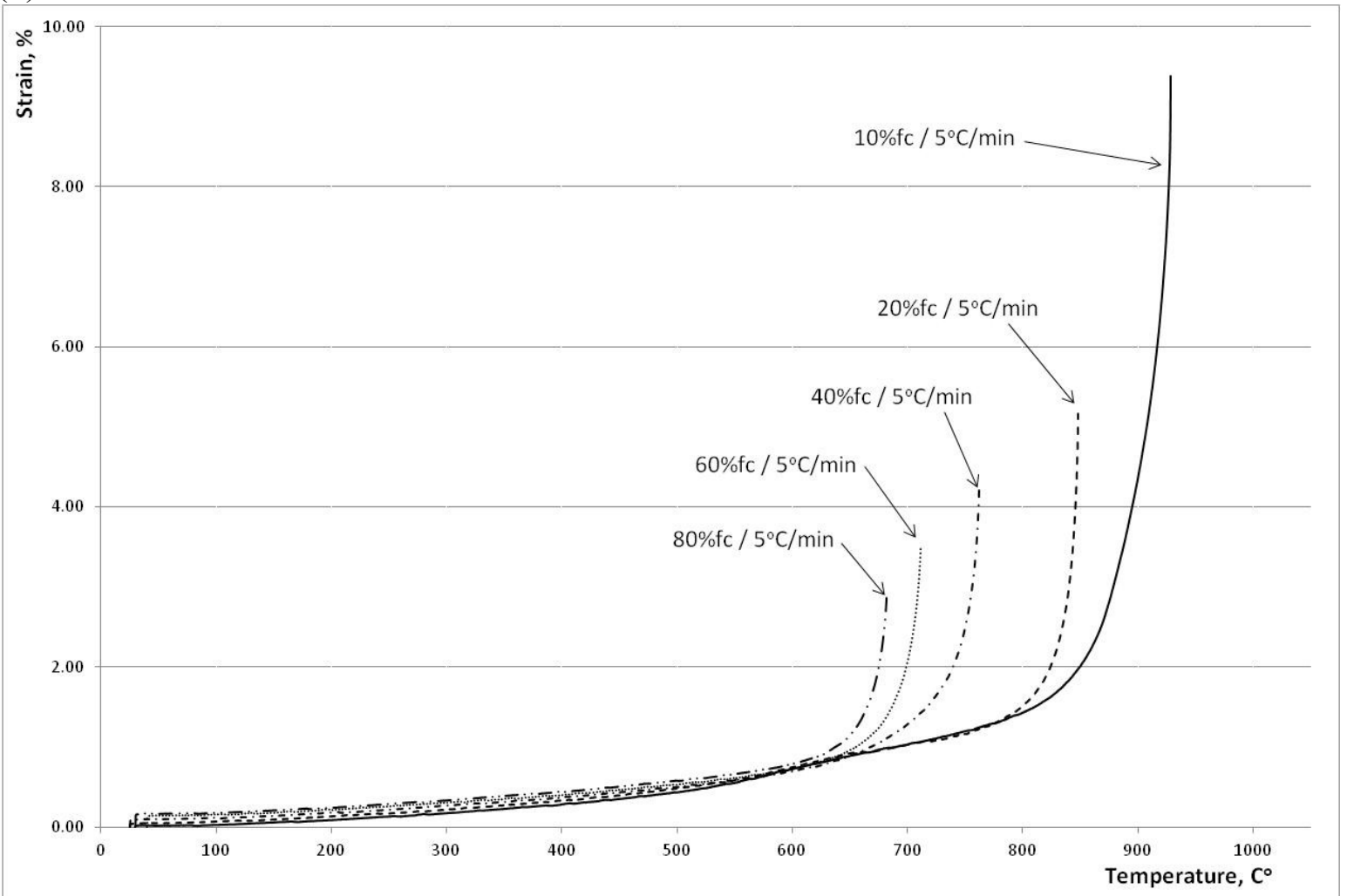

Figure 7: The effect of (a) heating rate and (b) of utilization factor from Group B transient tests. 


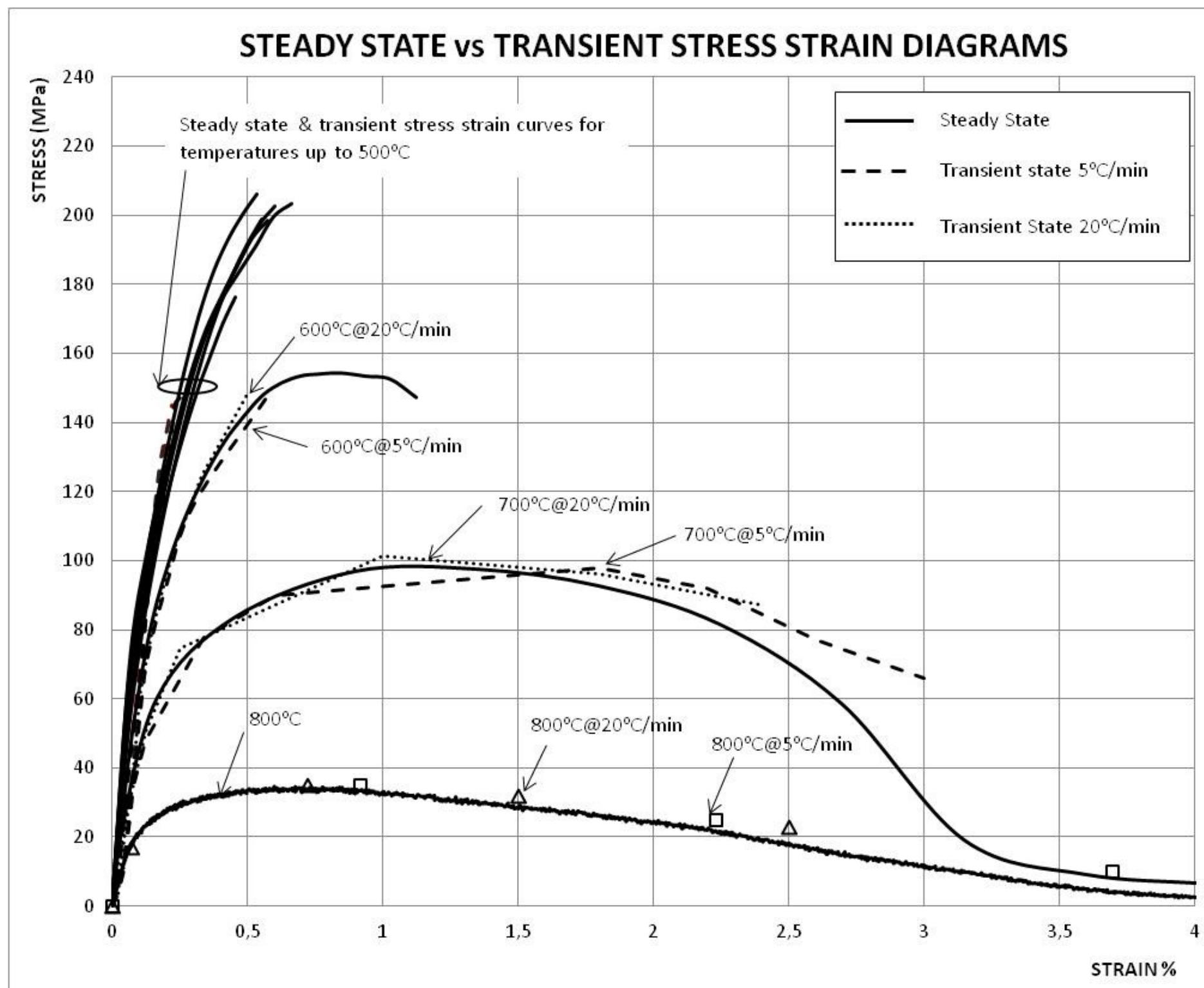

Figure 8: Comparison of stress-strain curves from the steady-state and transient state tests

\subsection{Ultimate strength in tension}

The effect of temperature on the ultimate tensile strength, normalized to the ambient temperature value, is presented in Figure 9a. The transient test strength values are higher than the steady state values and the transient tests conducted at $20^{\circ} \mathrm{C} / \mathrm{min}$ are slightly higher than those tested at $5^{\circ} \mathrm{C} / \mathrm{min}$. 
The strength reduction factor - temperature relationship of EN 1993-1-2 [36] for low carbon steel gives a safe low bound to the transient test results. The steady state test results give similar strength reduction factors as EN 1993-1-2 [36] for steel at temperatures higher than $400^{\circ} \mathrm{C}$. However, at lower temperatures up to $400^{\circ} \mathrm{C}$, there are some scatters in the test results with the average showing no effect of temperature, which is consistent with EN 1993-1-2 [36]. This indicates that at low temperatures, there is little effect of temperature on the strength of cast iron and the inconsistence most probably occurred because of the brittle nature of cast iron and the effects of flaws (which is determined by the number, size, orientation etc of the flaws) on the strength of the material. For example, the ambient temperature strength values of the two duplicate test specimens (Group A) are 192 and $215 \mathrm{MPa}$.

In [24], the upper and lower bounds of the ultimate strength reduction factor were determined. They are shown in Figure 9a and are consistent with the present test results if including both steady state and transient tests.

When a metal structure (cast iron or steel) is subject to fire attack, the structure temperature is likely to be higher than $400^{\circ} \mathrm{C}$. Also, since the heating condition is close to the transient testing condition, the transient testing results are more relevant. Therefore, a practical solution is to use the same EN 1993-1-2 [36] strength reduction factors for steel as for cast iron.

\subsection{Yield stress}

Figure $9 \mathrm{c}$ shows yield stress $(0.2 \%$ proof stress $)$ reduction factor - temperature relationships. Also plotted in Figure 9c are the lower and upper bounds suggested in [24], 
the EN 1993-1-2 curves for Young's modulus and yield strength of steel. The test results (including both steady-state and transient tests) are consistent with lower and upper bounds of [24]. The EN 1993-1-2 curve for Young's modulus of steel can be safely used to represent the $0.2 \%$ proof stress reduction factor - temperature relationship for cast iron. However, at temperatures exceeding $500^{\circ} \mathrm{C}$, in the EN1993-1-2 yield strength reduction factor - temperature relationship gives better approximation to the test results.

\subsection{Young's modulus}

Figure $9 \mathrm{~b}$ compares the secant modulus at $0.2 \%$ proof stress reduction factor temperature relationship with EN 1993-1-2 relationship for Young's modulus of steel. The secant modulus is calculated from the following relationship:

$\mathrm{E}=\sigma_{0,2 \%} / \varepsilon_{0,2} \%$

where $\sigma_{0,2} \%$ and $\varepsilon_{0,2} \%$ are the $0,2 \%$ proof stress and the corresponding strain respectively.

The results in Figure 9b suggest that the EN 1993-1-2 [36] relationship for Young's modulus of steel is a safe lower bound approximation.

3.5 Elongation at the maximum stress (ultimate strength)

Figure $9 \mathrm{~d}$ presents elongations at the maximum stresses. There is large variation among the test results at the same temperature. However, a conservative value of $\varepsilon_{\mathrm{u}}=0,5 \%$ may be considered. Alternative, the failure strain may be taken as unchanged at ambient temperatures. 


\subsection{Elongation at failure}

At low temperatures (not exceeding $400^{\circ} \mathrm{C}$ ), the maximum elongation at failure is almost the same as the elongation at the maximum stress, indicating that cast iron has little ductility and fractures once it has reached its maximum stress. At high temperatures, cast iron becomes more ductile and fracture is delayed after reaching the maximum stress. Figure 9e plots the maximum elongations. It shows that there is a good level of consistence among different tests results at the same temperature. The following equation (Eq. (2)) gives a close approximation to the test results:

$\left.\begin{array}{l}\text { For } 20^{\circ} \mathrm{C} \leq \theta \leq 400^{\circ} \mathrm{C} \\ \varepsilon_{\mathrm{f}}=\varepsilon_{\mathrm{t}, 20} \\ \text { For } 400^{\circ} \mathrm{C}<\theta \leq 700^{\circ} \mathrm{C} \\ \varepsilon=\varepsilon_{\mathrm{t}, 20}+\varepsilon_{\mathrm{t}, 20}\left(\theta-400^{\circ} \mathrm{C}\right) / 100 \\ \text { For } 700^{\circ} \mathrm{C}<\theta \leq 900^{\circ} \mathrm{C} \\ \varepsilon=4 \varepsilon_{\mathrm{t}, 20}+3 \varepsilon_{\mathrm{t}, 20}\left(\theta-700^{\circ} \mathrm{C}\right) / 100\end{array}\right\}$

The stress at fracture can be taken equal to the strength for temperatures up to $400^{\circ} \mathrm{C}$. For higher temperatures, this value can be taken as $50 \%$ of the strength although there is large scatter within the experimental data. 
(a)

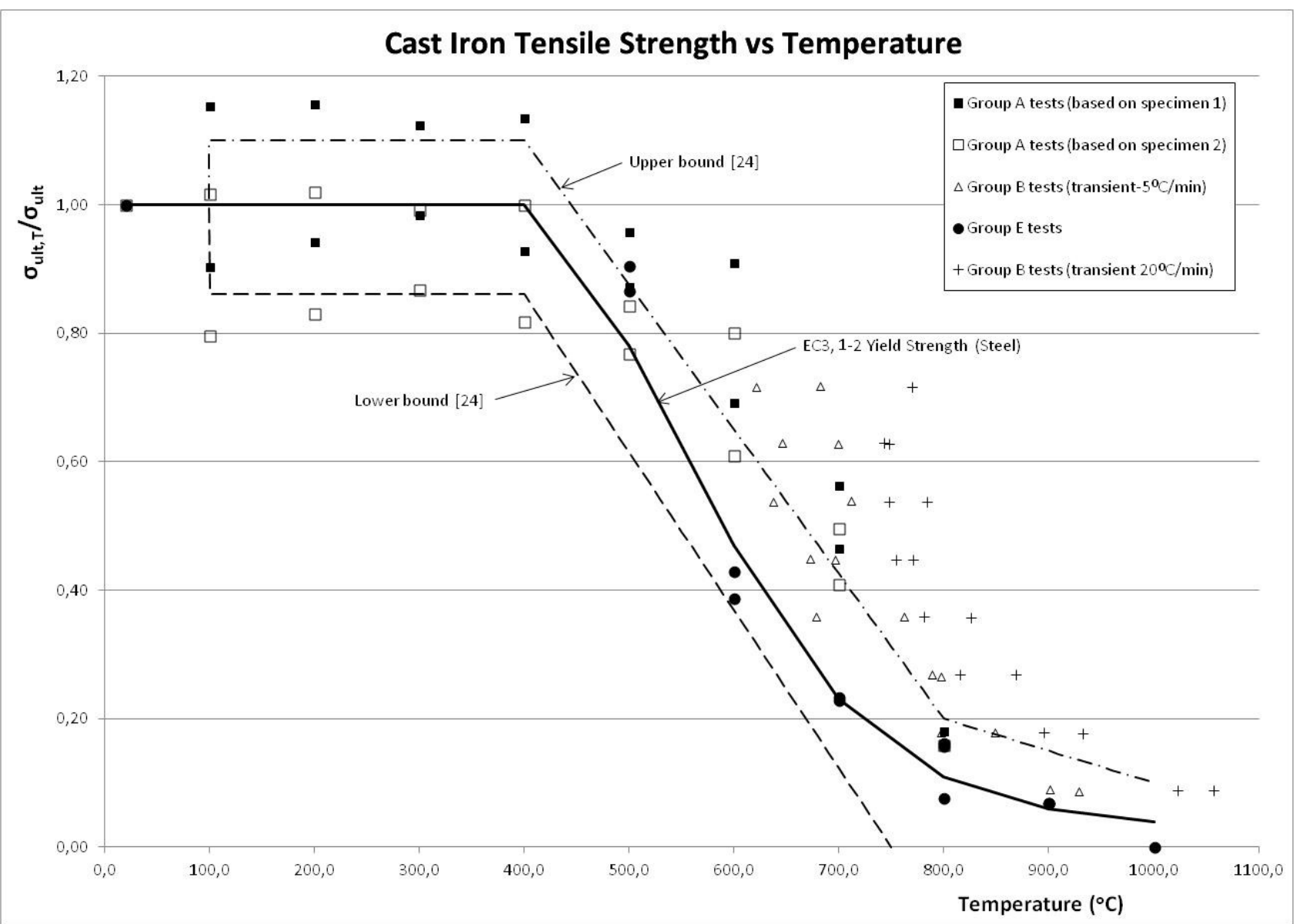


(b)

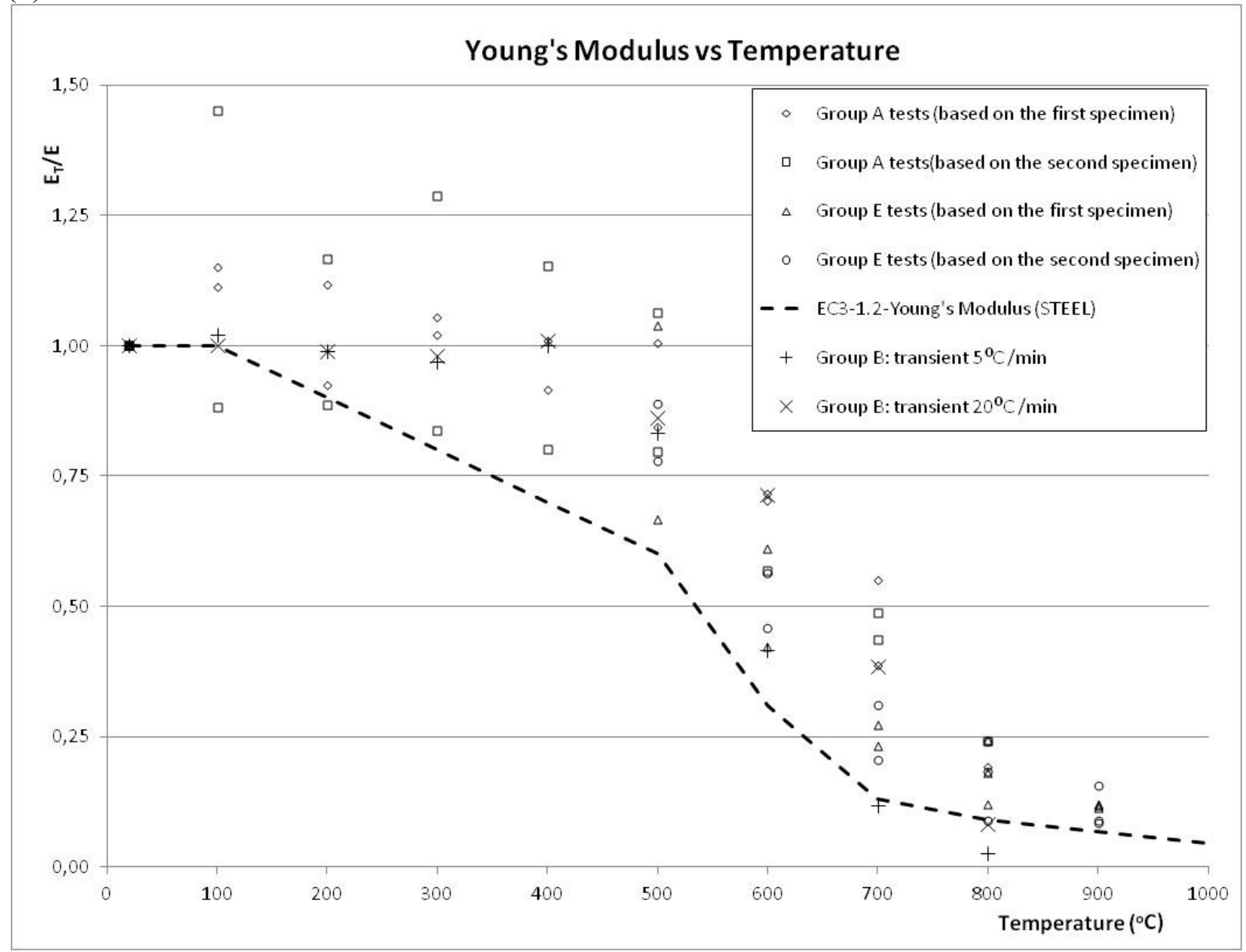


(c)

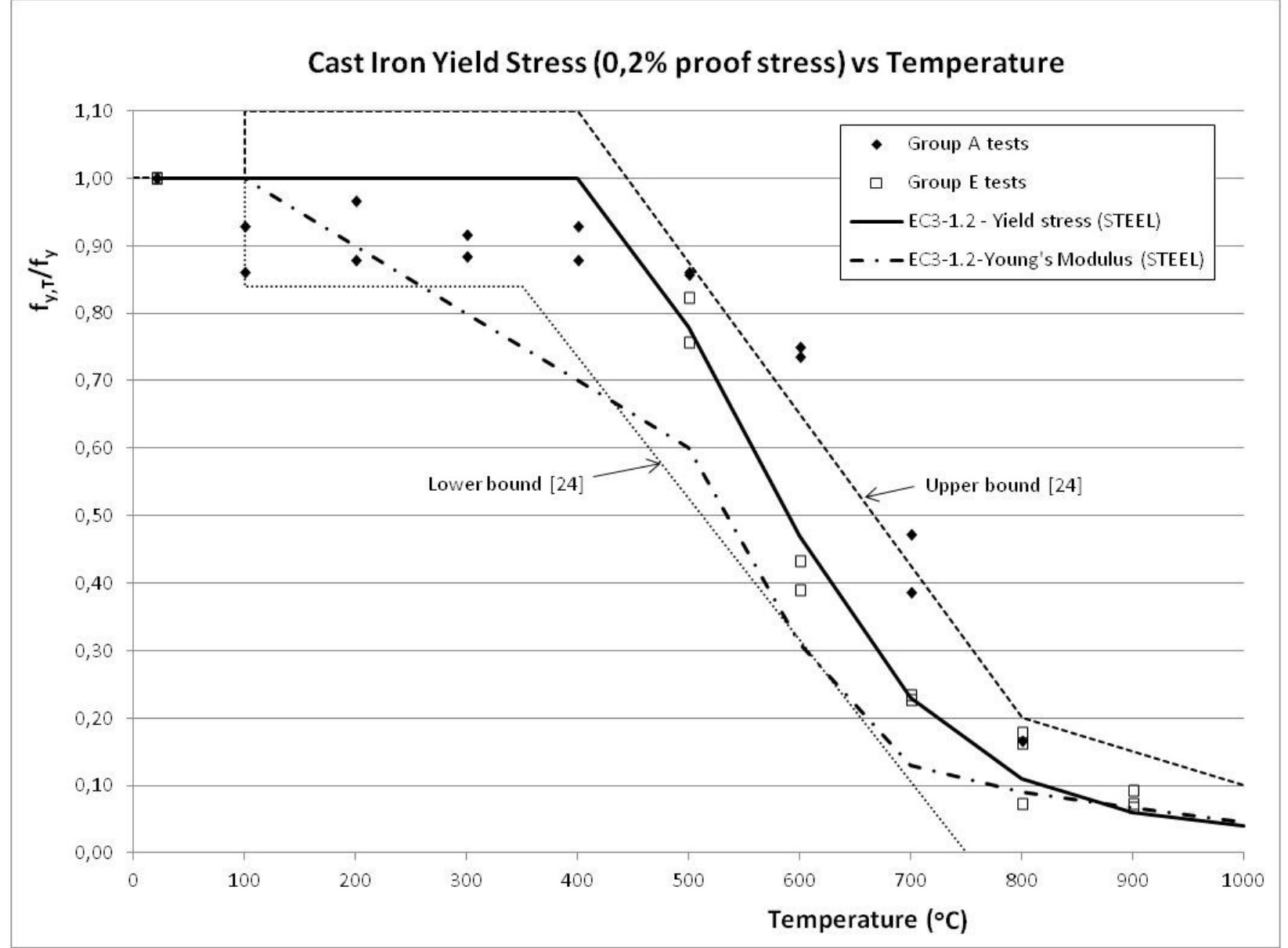


(d)

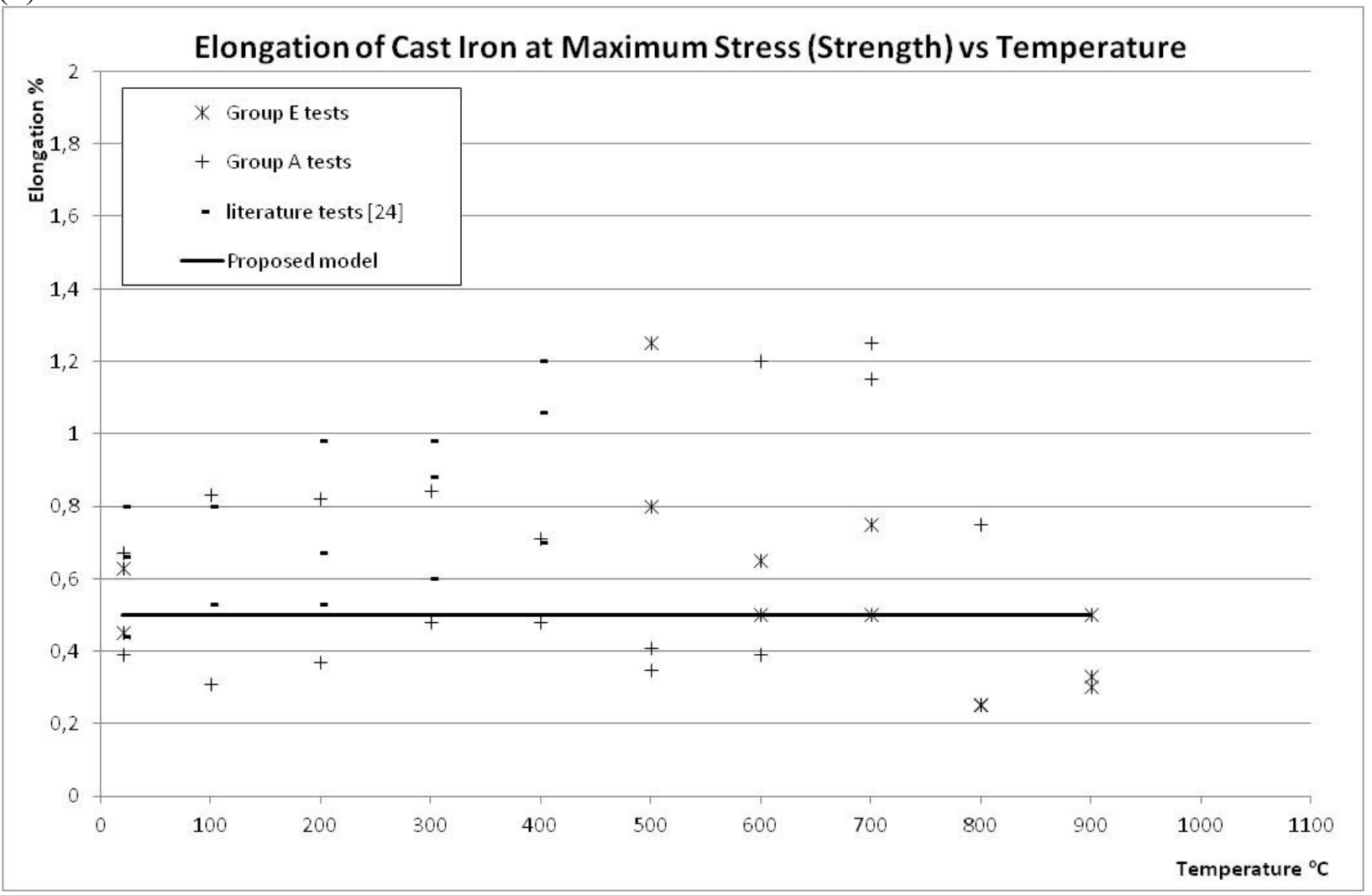

(e)

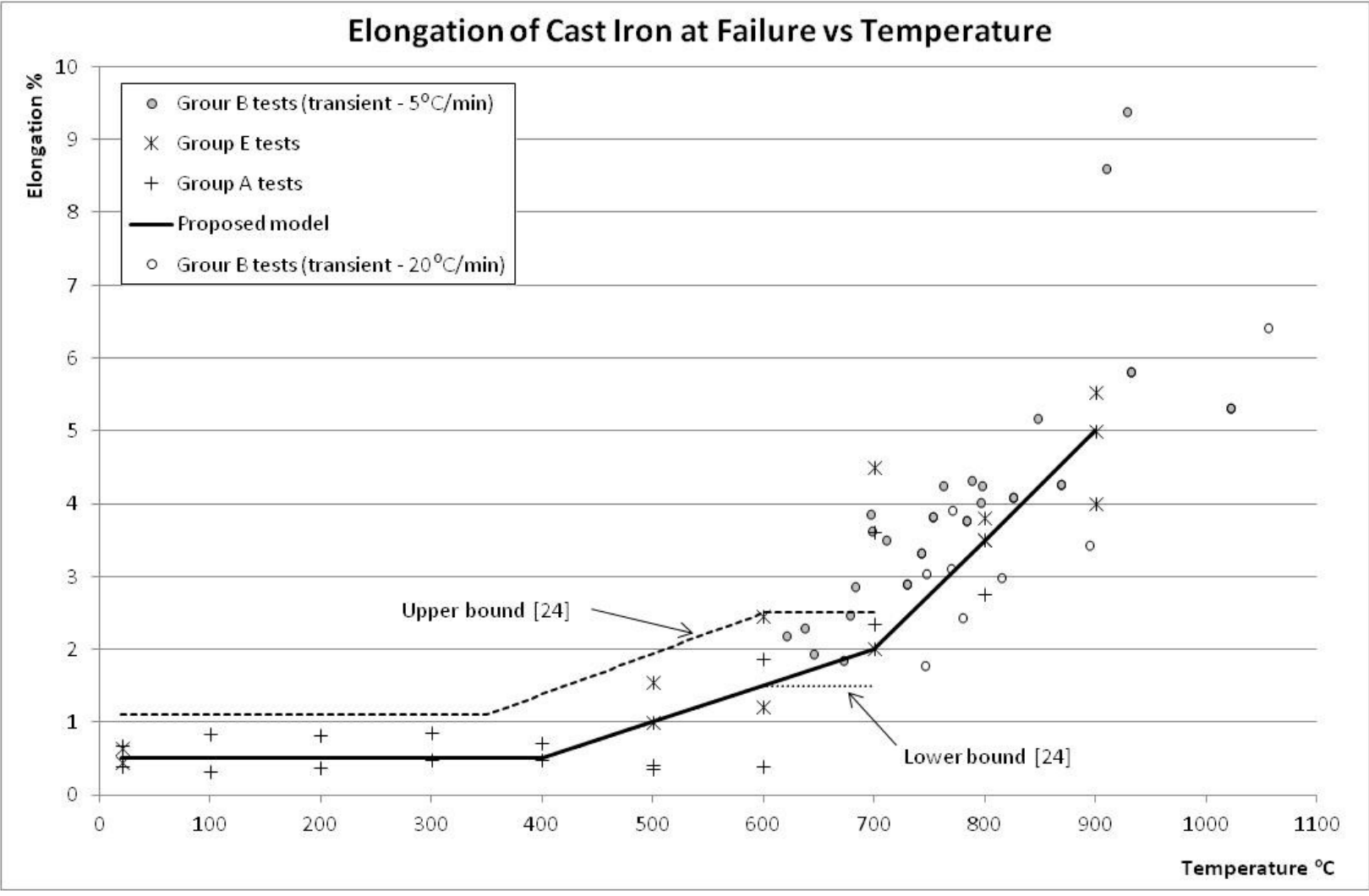


Figure 9: Test results in tension for: (a) strength, (b) Secant modulus at $0.2 \%$ proof stress, (c) $0.2 \%$ proof stress and (d) elongation at maximum stress (strength), (e) elongation at failure

\subsection{Proposed stress-strain relationship}

For simplicity, a tri-linear (bilinear at temperatures not exceeding $400^{\circ} \mathrm{C}$ ) relationship may be used for the stress-strain relationship of cast iron at elevated temperatures. Figure 10 shows this stress-strain curve and how the key points can be determined using the recommendations suggested in the previous sections.

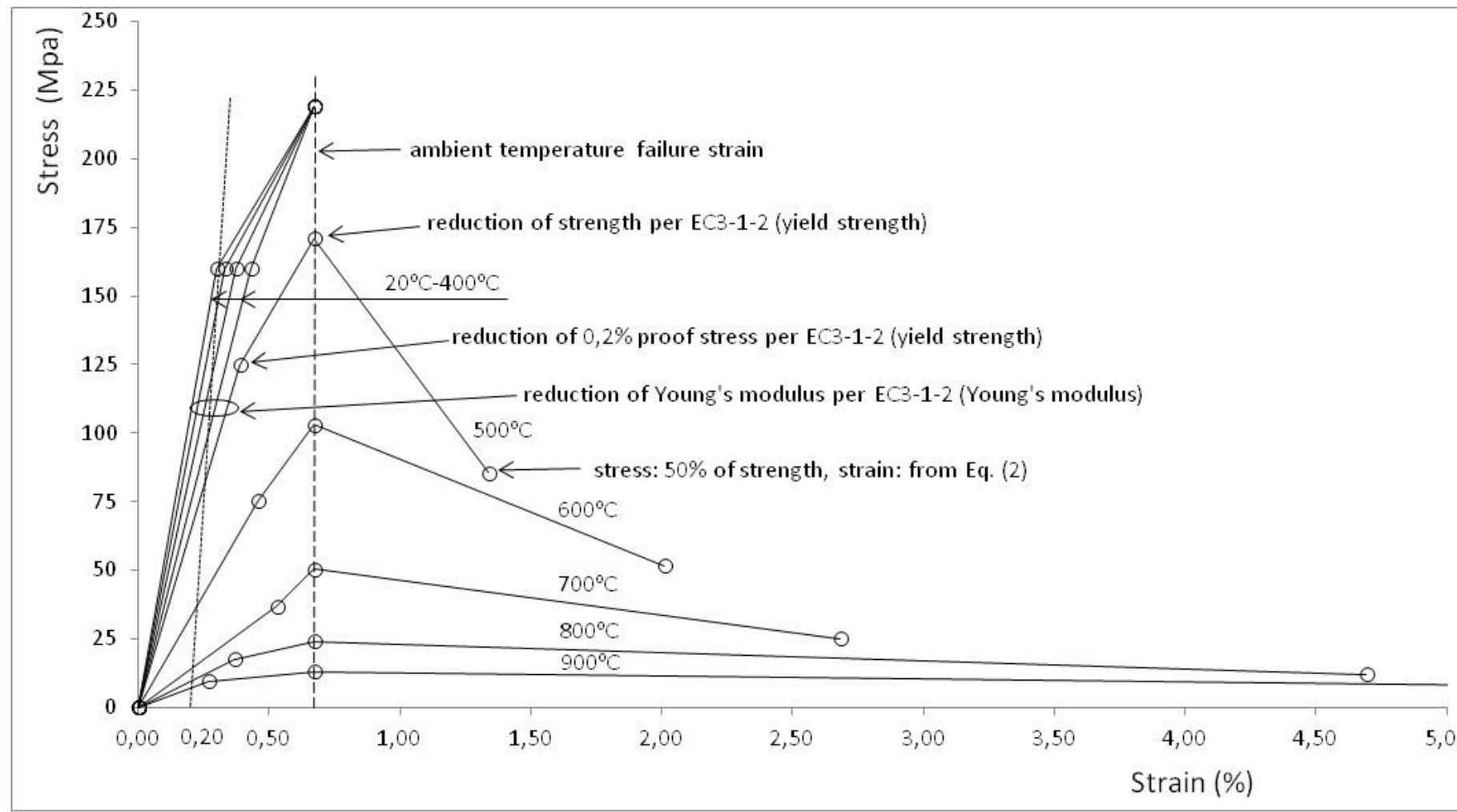

Figure 10. Proposed stress strain temperature relationship of cast iron in tension 


\section{Mechanical properties of cast iron in compression at elevated temperatures}

\subsection{General}

The stress-strain diagram of cast iron in compression is totally different from that in tension. This happens because the flaws are closing in compression and they affect less the overall behaviour (e.g. stiffness and strength) of cast iron.

Figure 11 shows typical stress-strain diagram of cast iron in compression. Contrary to the tensile behaviour, the modulus of elasticity and a proportional limit can be clearly defined. Conventionally, the yield strength is also assumed to be the $0.2 \%$ proof stress. Beyond the yield point, the material exhibits strain hardening which is defined by the hardening modulus $\mathrm{E}_{\mathrm{T}}$. Material failure is reached at the stress $\mathrm{f}_{\mathrm{u}}$. However, this point could not be accurately determined from all conducted experiments because the expansiometer had a limit of about 5\% in compression at elevated temperatures. In order to gain some quantitative data on the strain limit of cast iron in compression, two additional tests at ambient temperatures were carried out. In these tests, thicker specimens (Figure 1d) were used to reduce the influence of buckling. These specimens were prepared from the grip zones of the ambient temperature test specimens of Group A. Figure $12 \mathrm{a}$ presents the stress-strain diagrams of these two experiments and Figure $12 \mathrm{~b}$ shows the failure mode. Shear failure occurred at approximately 10\% compression strain. Because cast iron becomes more ductile at higher temperatures, the failure strain of cast iron in compression at elevated temperatures can be conservatively taken as $10 \%$. The stress-strain curves show a relatively steep declining branch which resulted from the residual friction resistance of the failure surface. 
Figure 13a presents complete steady-state test results and Figure 13b compares some of the steady-state test results with transient test results. During the transient tests, the stress in the test specimen increased due to restrained thermal expansion. This caused the strain to exceed $5 \%$ in many of the high temperature $\left(>500^{\circ} \mathrm{C}\right)$ tests. As explained earlier, such data are unreliable. Therefore, the available data for the high temperatures is sporadic. Nevertheless, the comparison in Figure 13b suggests that the steady-state and transient test results are reasonably close. Therefore, the properties of cast iron in compression are based on the steady-state test results.

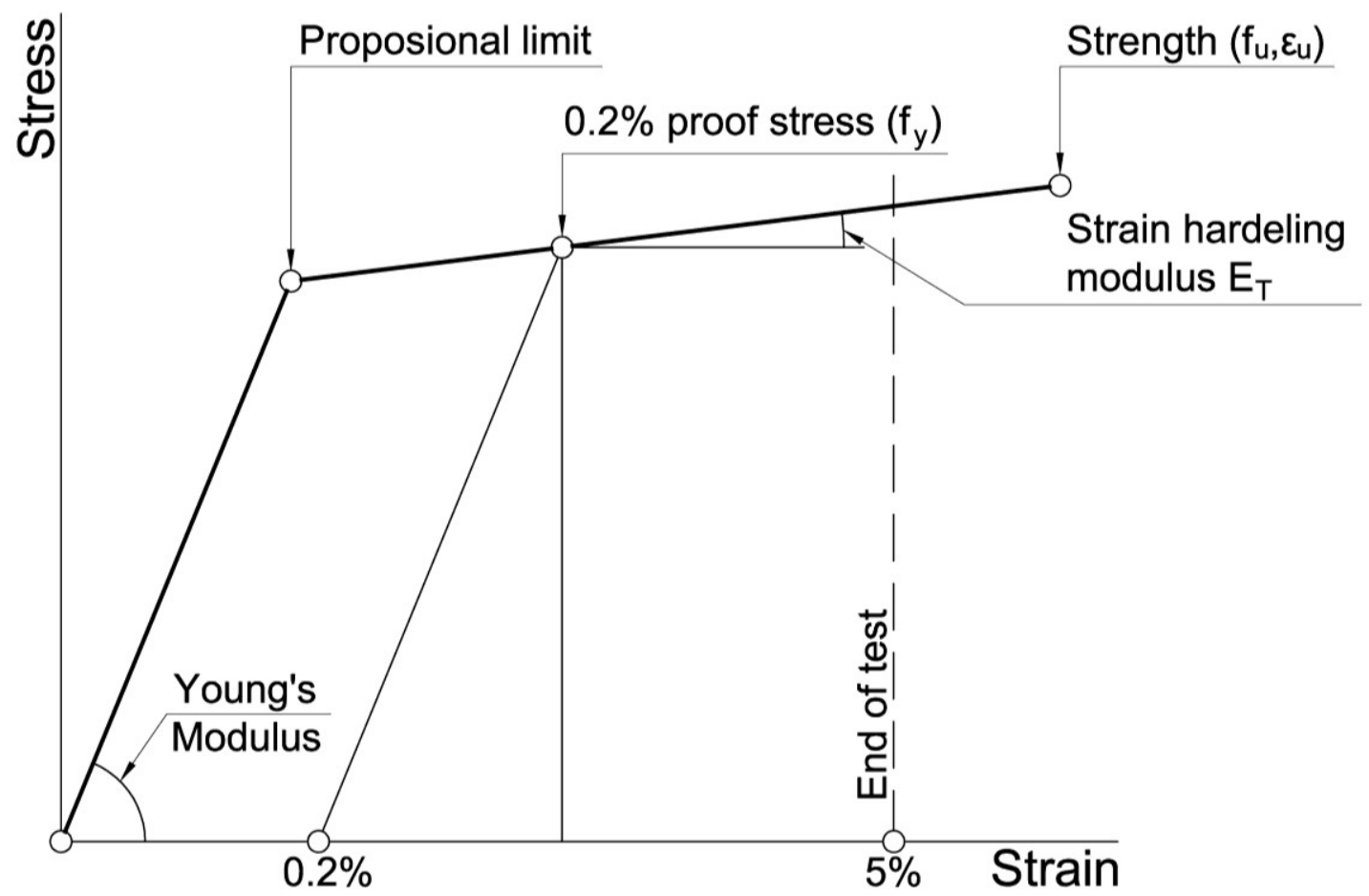

Figure 11: Typical stress-strain diagram of cast iron in compression 


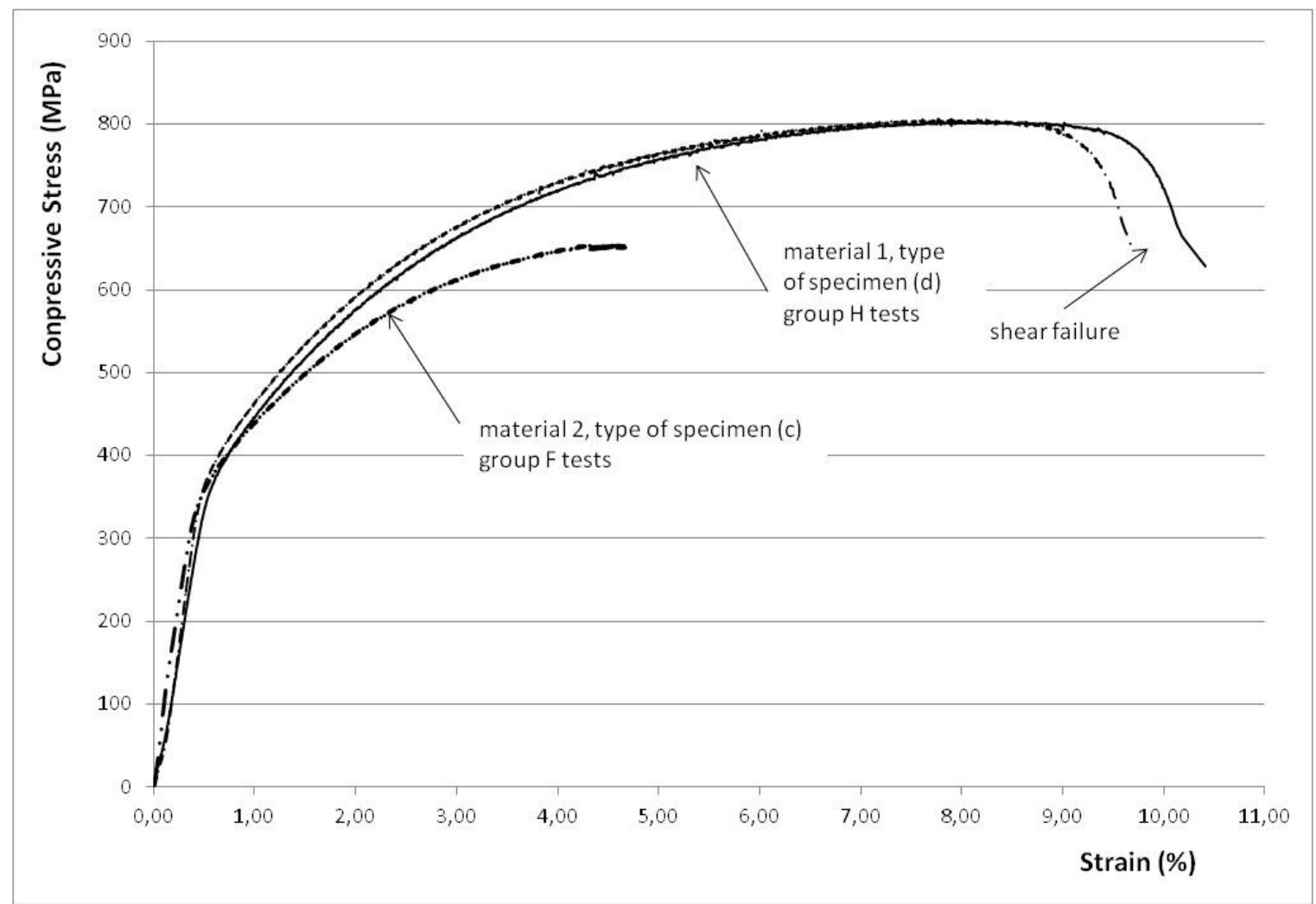

a)

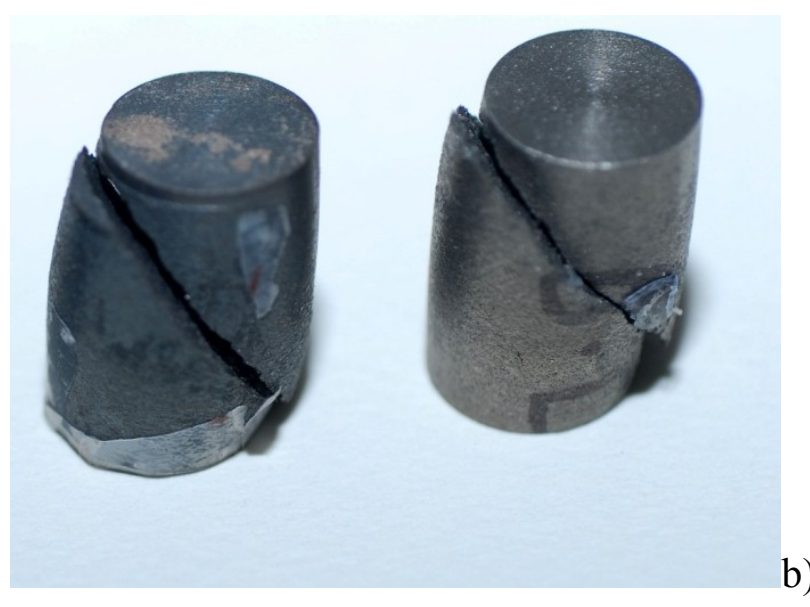

Figure 12: a) Ambient temperature stress-strain diagrams of cast iron (Group F and $\mathrm{H}$ tests) and b) shear failure mode of Group H specimens. 


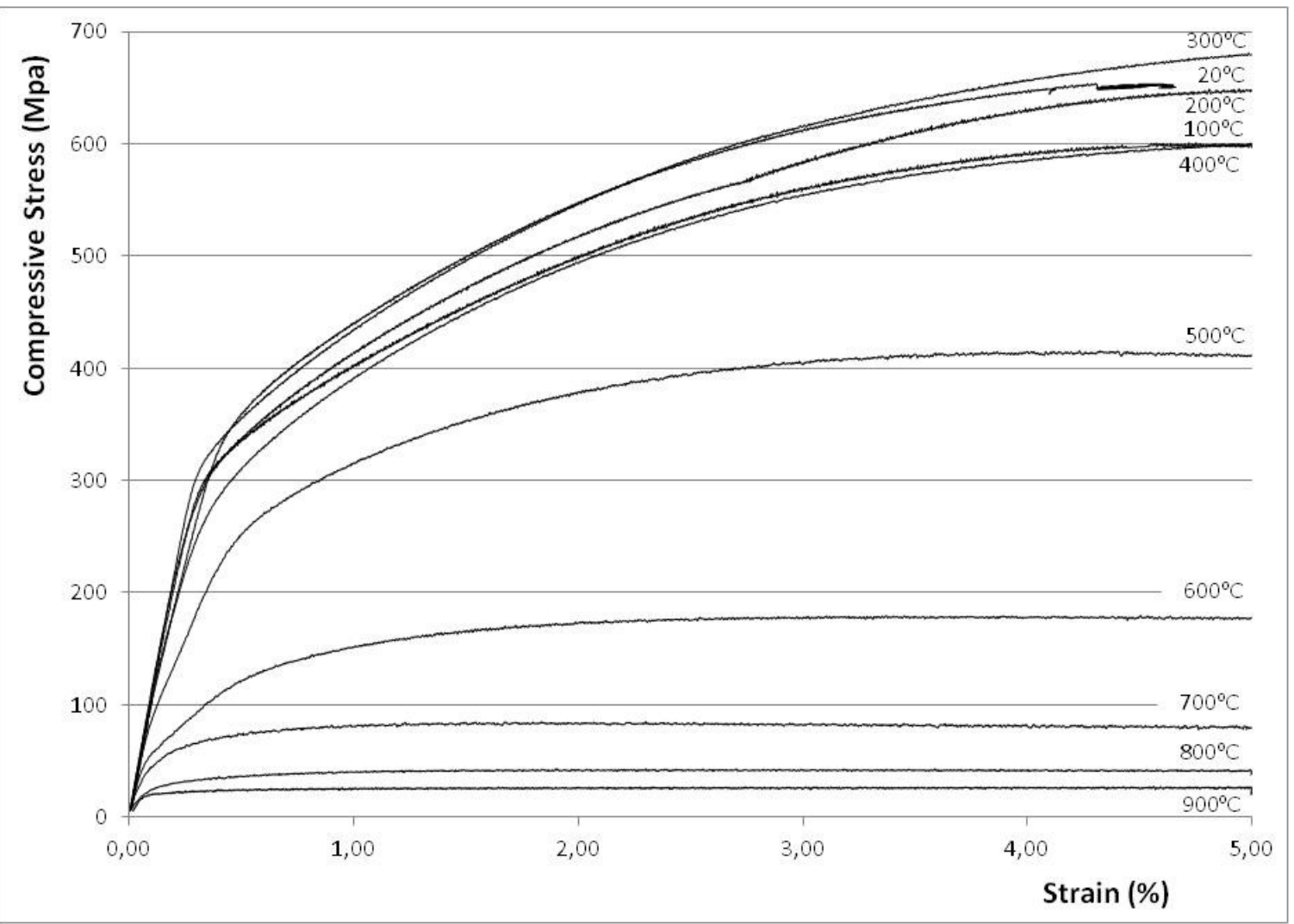

a)

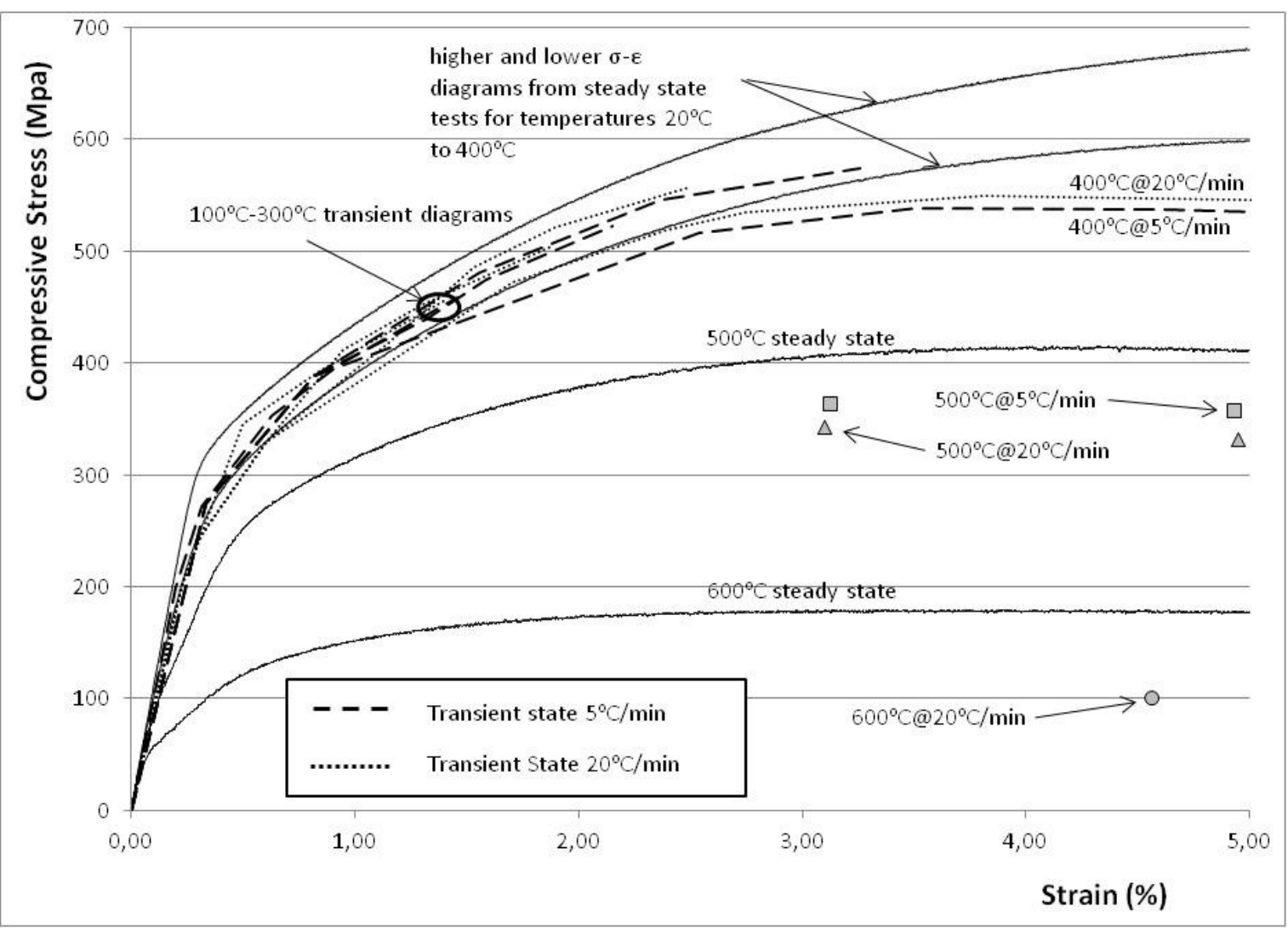


Figure 13: (a) Steady state stress-strain curves and (b) Comparison of steady-state and transient test stress-strain curves in compression. 


\subsection{Stress-strain curves in compression}

Figure 13a shows that at temperatures not exceeding $400^{\circ} \mathrm{C}$, there is little change in the stress-strain diagrams. At higher temperatures there is, as expected, a gradual decrease in the values of all the mechanical properties. Figure 14 shows how the key parameters of the stress-strain diagram change at increasing temperatures. Plotted in Figure 14 are also the relevant relationships for steel from EN 1993-1-2 [36].

\subsection{Young's modulus}

Figure 14(a) shows reduction of the Young's modulus with temperature. The Young's modulus in compression is obtained as the initial tangent modulus. Figure 14(a) indicates that the EN 1993-1-2 Young's modulus - temperature relationship for steel is a close and safe approximation for cast iron in compression.

\subsection{Proportional limit}

In compression, cast iron exhibited a prolonged phase of approximately linear stressstrain behaviour. The proportional limit of stress is approximately twice the yield stress (0.2\% proof stress) in tension. Section 3.3 has suggested using the EN 1993-1-2 yield strength reduction factor - temperature relationship for steel. The results in Figure 14(b) confirm this suggestion. In contrast, the EN 1993-1-2 proportional stress reduction factor - temperature relationship is too conservative.

\subsection{Yield stress $(0,2 \%$ proof stress $)$}

Figure 14(c) presents the reduction of yield stress with temperature. The steady state results are slightly lower than the transient test results. The transient test results are very 
similar to the EN 1993-1-2 results for steel. Therefore, the EN 1993-1-2 yield strength reduction factor - temperature relationship for steel can be used for cast iron in compression.

4.6 Ultimate strength in compression and strain hardening The ultimate strength could not be determined from the elevated temperature experiments as explained in section 3.3, except for that at ambient temperature. However, the analysis of results for cast iron in compression suggests that its relative behaviour, between elevated and ambient temperatures, follow that of steel. Therefore, it is proposed that the reduction factors for ultimate strength of steel in tension in EN 1993-1-2 be used for cast iron in compression. The ultimate strength can then be used to determine the strainhardening segment of the stress-strain curve in compression by limiting the strain at $10 \%$, as shown in Figure 12(a). 
a)

\section{Young's modulus vs Temperature}

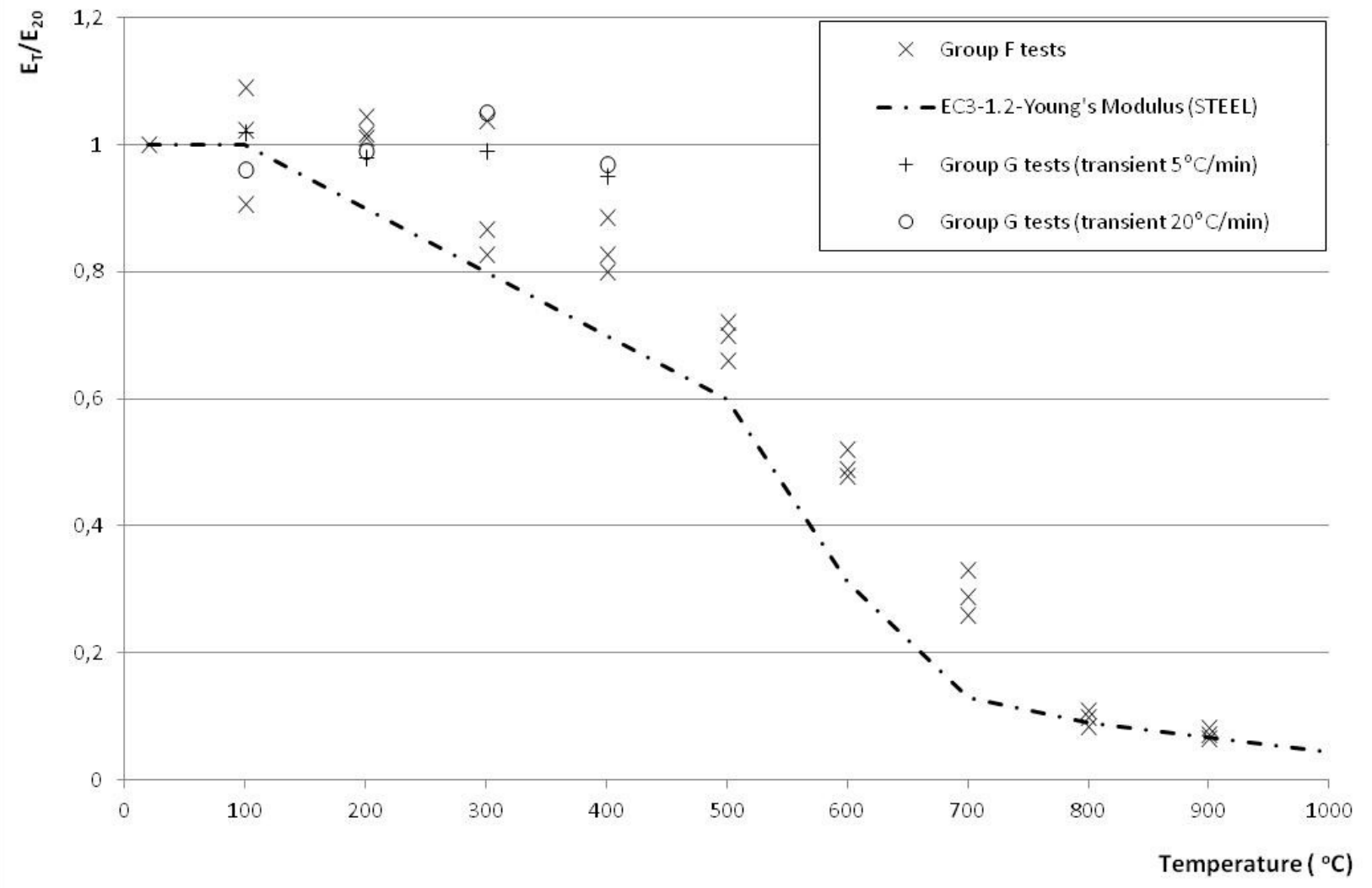


b)

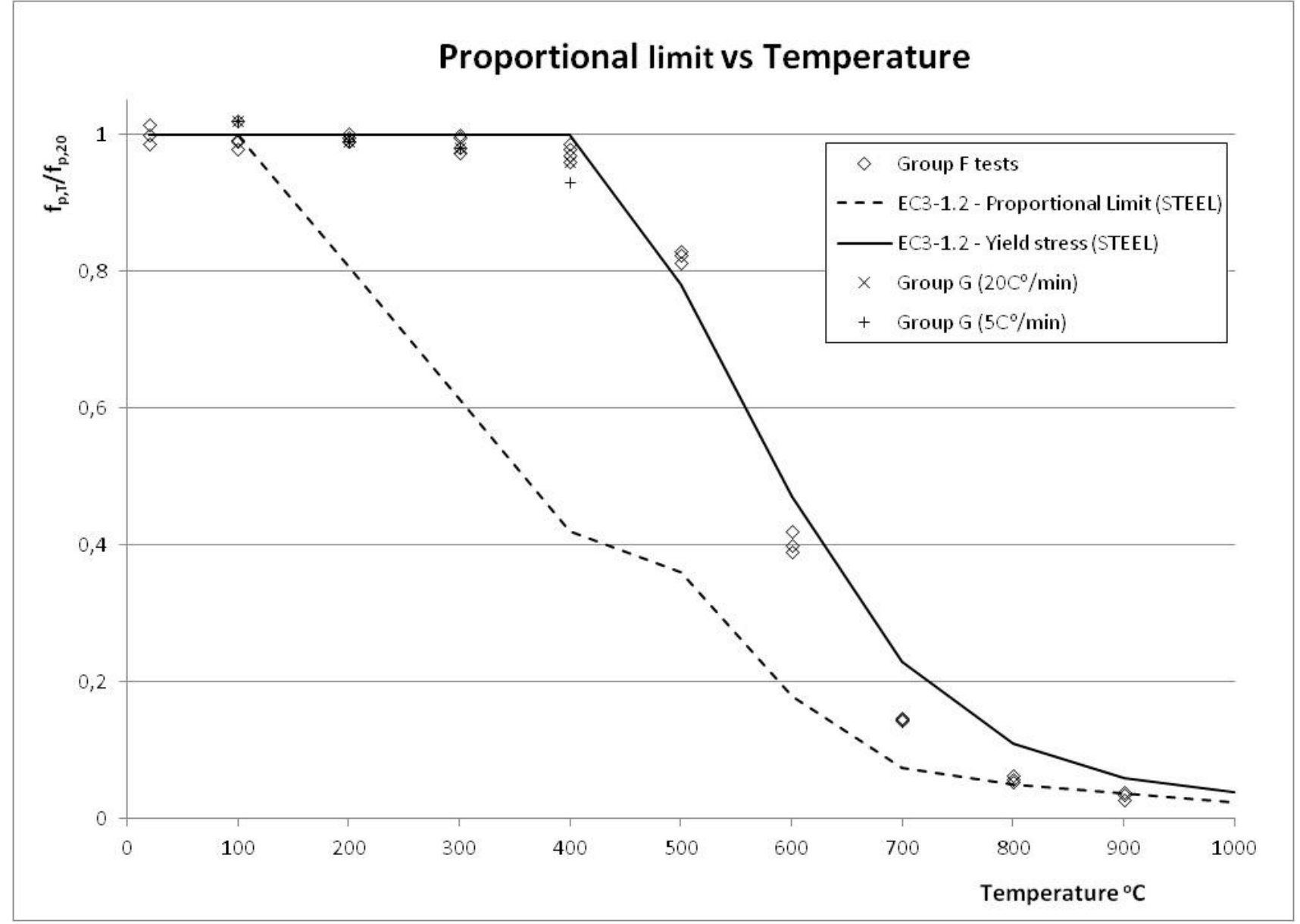


c)

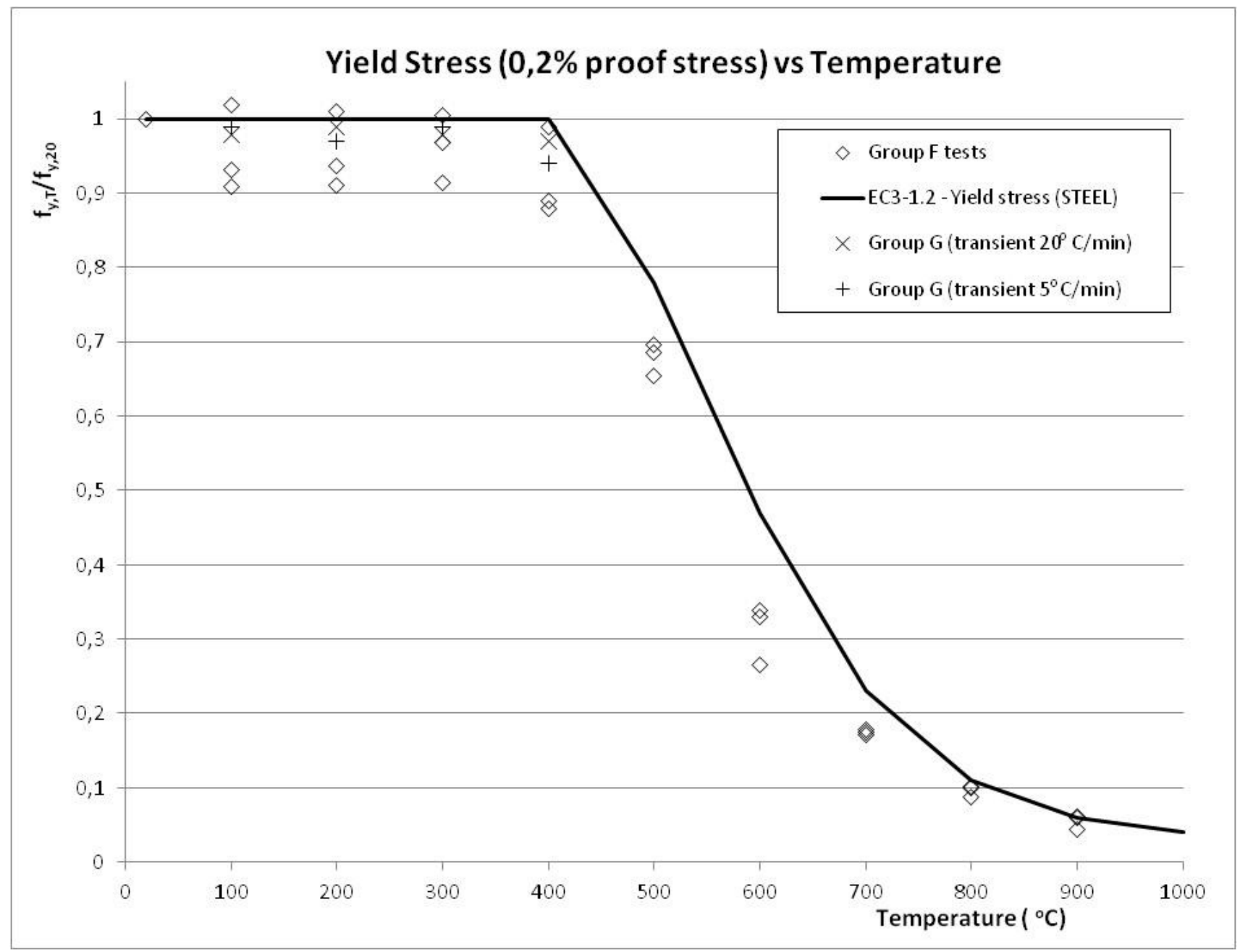

Figure 14: Reduction factor - temperature relationships for cast iron in compression; (a) Young's modulus; (b) proportional limit; (c) Yield strength

4.7 Stress-strain relationship in compression

Based on the discussions above, the stress-strain relationships of cast iron in compression (Figure 15) can be constructed using a trilinear curve as described below:

(1) Initial linear relationship until the proportional limit;

(2) Linear relationship from the proportional limit until $0,2 \%$ proof stress;

(3) Final linear relationship from the $0,2 \%$ proof stress to the ultimate strength at $10 \%$ strain. 


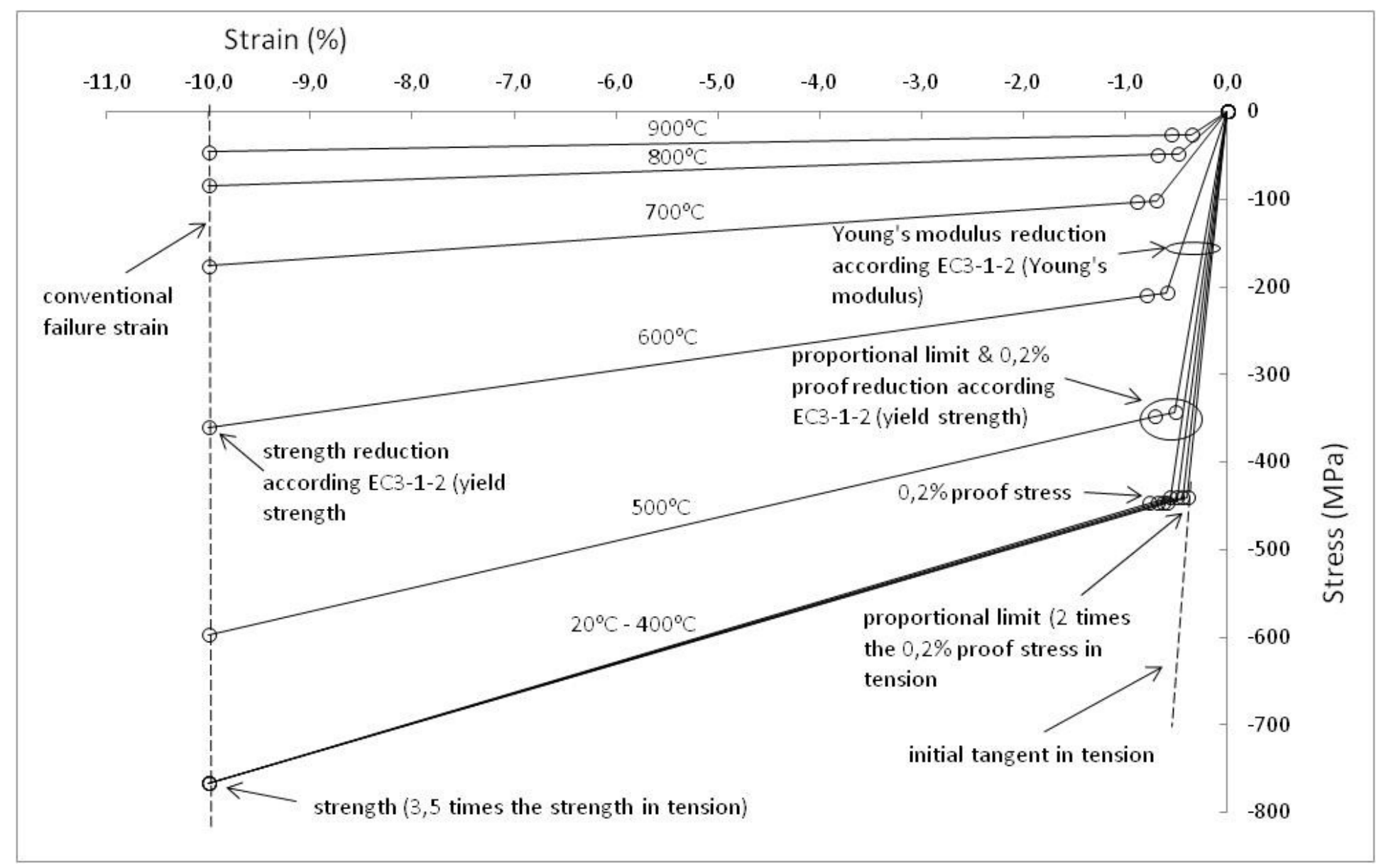

Figure 15 Proposed stress-strain relationships of cast iron in compression.

\section{Coefficient of thermal expansion of structural cast iron}

The coefficient of thermal expansion of cast iron was measured on three identical specimens of material 1 in Table 1, following the provisions of the American Standard ASTM E831-12 [37] with continuous monitoring of the specimen at increasing temperature. All the experiments were carried out using a 133459/TMA-7 Thermomechanical Analyzer (TMA). The initial temperature of the heating chamber was set at $10^{\circ} \mathrm{C}$ and the heating rate was $10^{\circ} \mathrm{C} / \mathrm{min}$.

The coefficient of thermal expansion was calculated using the following formula: 
$\alpha=\left(\mathrm{t}_{2}-\mathrm{t}_{1}\right) / \mathrm{t}_{1} *\left(\mathrm{~T}_{2}-\mathrm{T}_{1}\right)$

where (see Figure 16):

$\alpha=$ coefficient of thermal expansion, in $\mathrm{mm} / \mathrm{mm}^{\circ} \mathrm{C}$

$\mathrm{t}_{1}=$ thickness of specimen at point 1 , in $\mathrm{mm}$

$\mathrm{t}_{2}=$ thickness of specimen at point 2 , in $\mathrm{mm}$

$\mathrm{T}_{1}=$ temperature at point $1,{ }^{\mathrm{o}} \mathrm{K}$

$\mathrm{T}_{2}=$ temperature at point $2,{ }^{\circ} \mathrm{K}$.

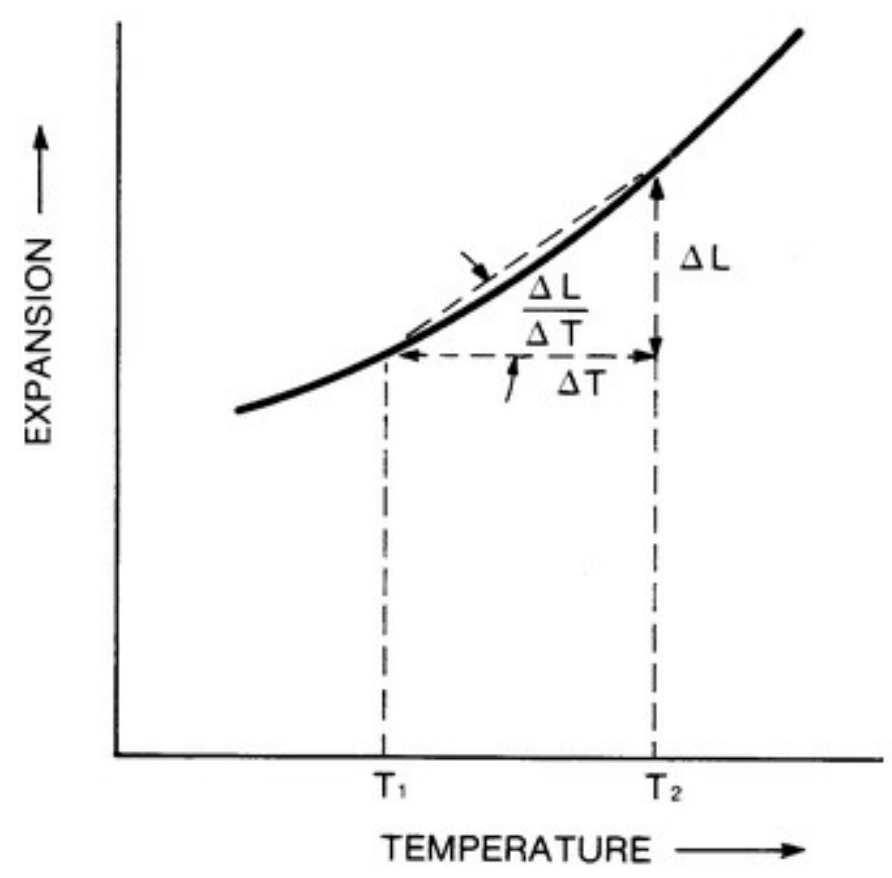

Figure 16: Calculation of thermal expansion [37]

In addition, a specimen with the shape shown in Figure 1(c), made from material 2 (Table

1), was heated without imposing any load to measure its thermal strains. 
Figure 17(a) presents the coefficient of thermal expansion results for each specimen and also plots the average variation of the three test specimens. Also shown in Figure 17(a) is the EN 1993-1-2 [33] relationship for steel. The experimental results follow the same trend of increasing coefficient of thermal expansion with increasing temperature as for steel. However, the test results for cast iron are lower than those of steel at low temperatures and higher than those of steel at high temperatures.

Figure 17(b) compares the total thermal strain between the average test results and the EN 1993-1-2 values for steel. The two sets of results are close. Because it is the total thermal strain, not the coefficient of thermal strain, that will influence cast iron structural behaviour in fire, it is proposed using the EN 1993-1-2 thermal strain values of steel for cast iron. The test results for cast iron do not show phase change effect around $750^{\circ} \mathrm{C}$. However, since this temperature is very high and likely to be outside the range of practical interest, it is suggested not necessary to refine the results for cast iron. . 
a)

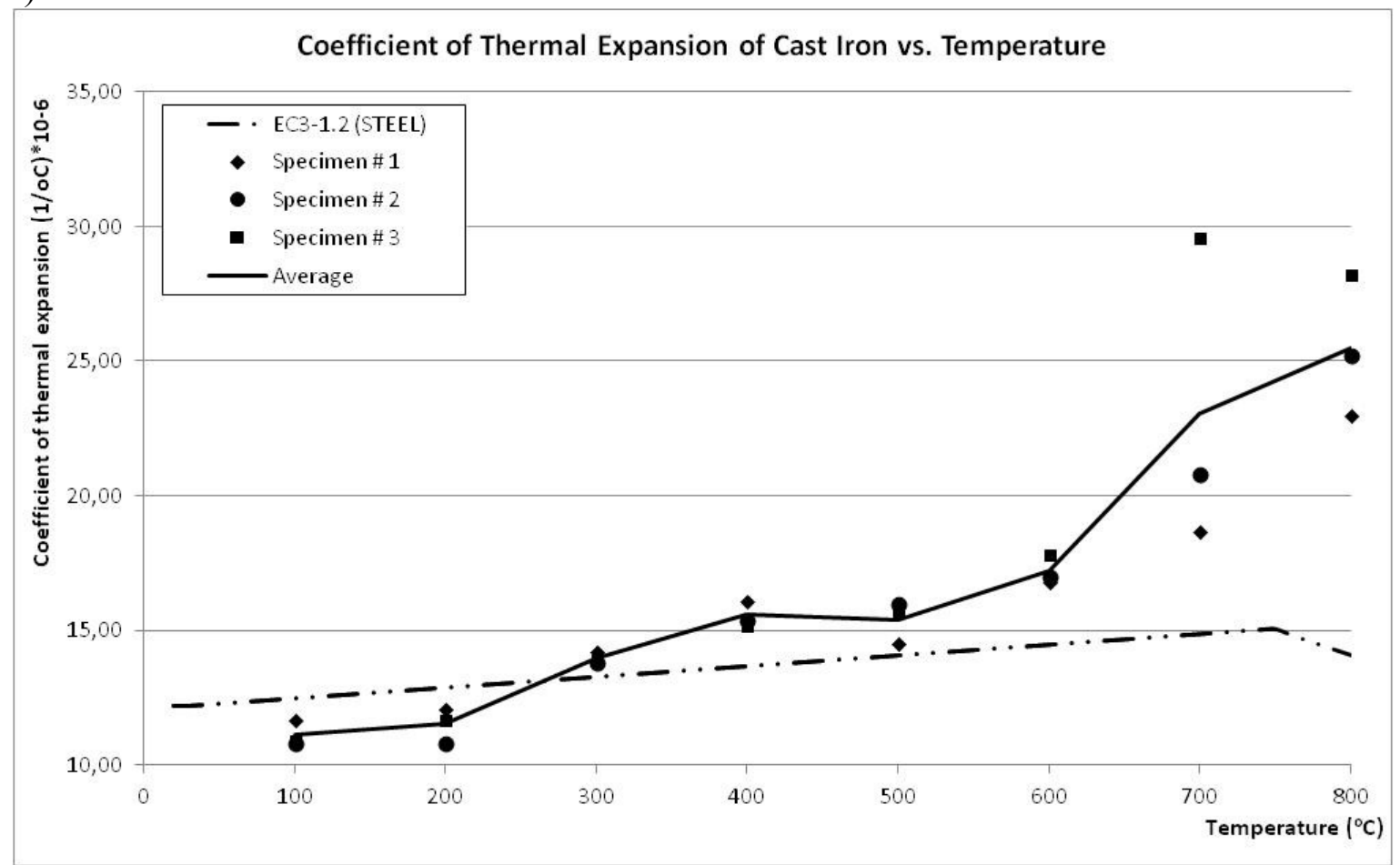

b)

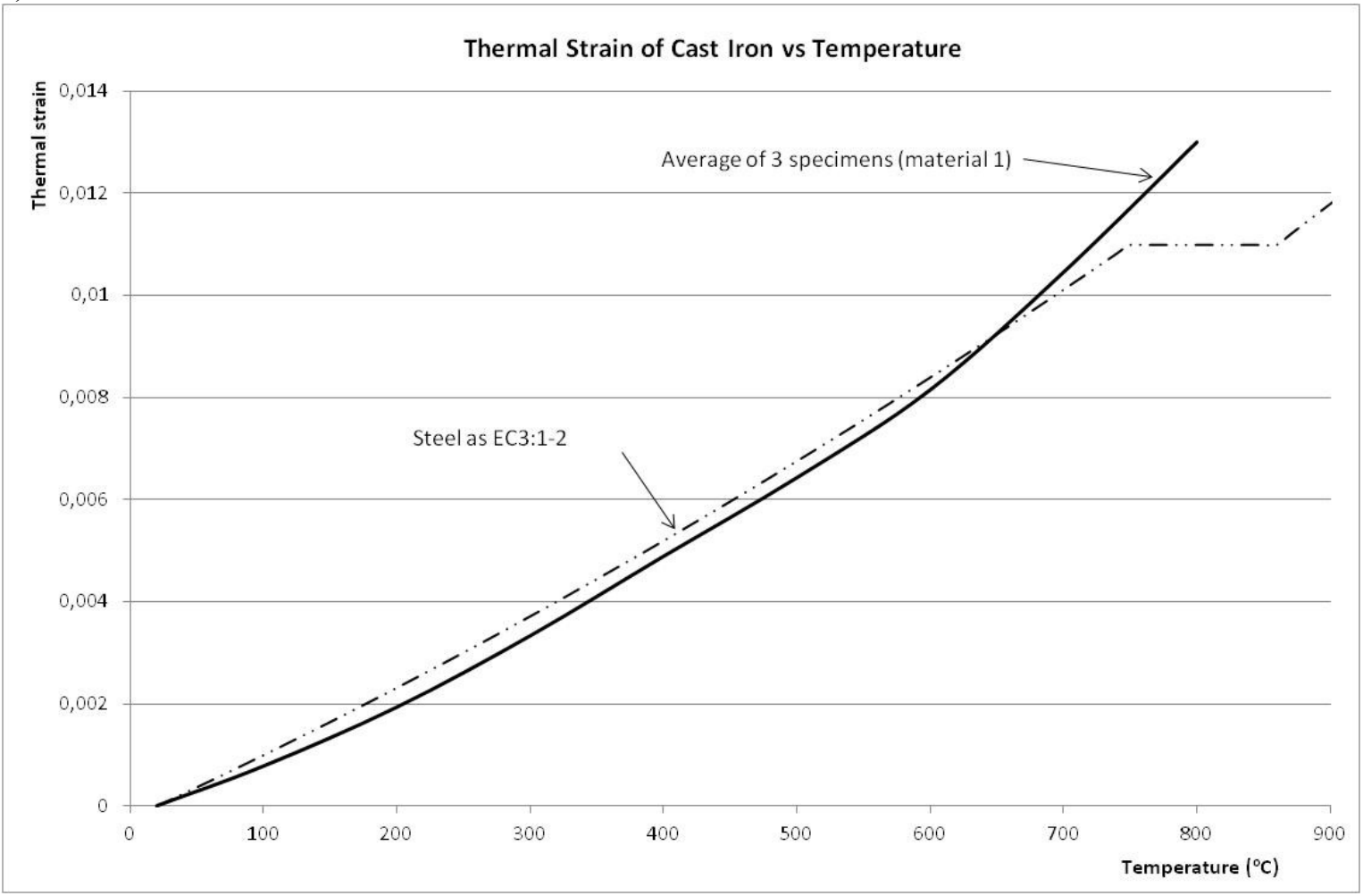

Figure 17: Comparison of a) thermal expansion variation with temperature and b) thermal strain variation with temperature 


\section{Residual strength of structural cast iron}

Cast iron structures are historic structures and are often preserved whenever possible, even after a fire damage. To assess whether a cast iron structure is reparable after fire damage, it is necessary to obtain mechanical properties of cast iron after cooling down. In particular, cast iron has been described as a material susceptible to thermal shock during fire-fighting [38]. So far, there is a complete lack of data in open literature.

In this research, two cooling method types (rapid cooling by water quenching and slow cooling in ambient air) were used for the Group D test specimens in Table 2. Figure 18 shows the heating and cooling histories of the specimens, for specimens being heated to $800^{\circ} \mathrm{C}$ and then cooled. Figure 19 shows the experimental residual strength results and compares them with experimental results for other types of steel $[39,40]$. These suggest that the cooling rate has some influence on the residual strength of cast iron. The test results show that the residual strength of cast iron remains practically unchanged up to $500^{\circ} \mathrm{C}$, then undergoes the maximum reduction (approximately $20 \%$ for slow cooling and $40 \%$ for rapid cooling) in the temperature region of $600^{\circ} \mathrm{C}$ to $700^{\circ} \mathrm{C}$ and then increases up to the ambient temperature value at $800^{\circ} \mathrm{C}$.

This is to be expected, because the heating and cooling process is a hardening procedure for metals [41]. According to [41], Austenite decomposes at temperatures around $720^{\circ} \mathrm{C}$. Depending on the cooling rate, Austenite may recompose (very slow cooling rate equilibrium conditions) or convert to pearlite or/and martensite (high cooling rates). The transformation of Austenite to pearlite / martensite increases the strength and hardness of the metal. Cast iron is not different [41] in behavior from eutectoid carbon steel, because 
a major portion of the carbon content is encountered in graphite flake form. Figure 20 illustrates the influence of cooling rate and the relevant transformations.

Cast iron structures were historically designed with very high safety factors (ranging from 3 to 12 according to [9], [23], [22], [43]). Therefore, this research suggests that despite the scatter in their mechanical properties, the reinstatement/reuse of cast iron structures after fire attack, in most cases, is feasible if no visible damage or distortion can be detected. 
(a)

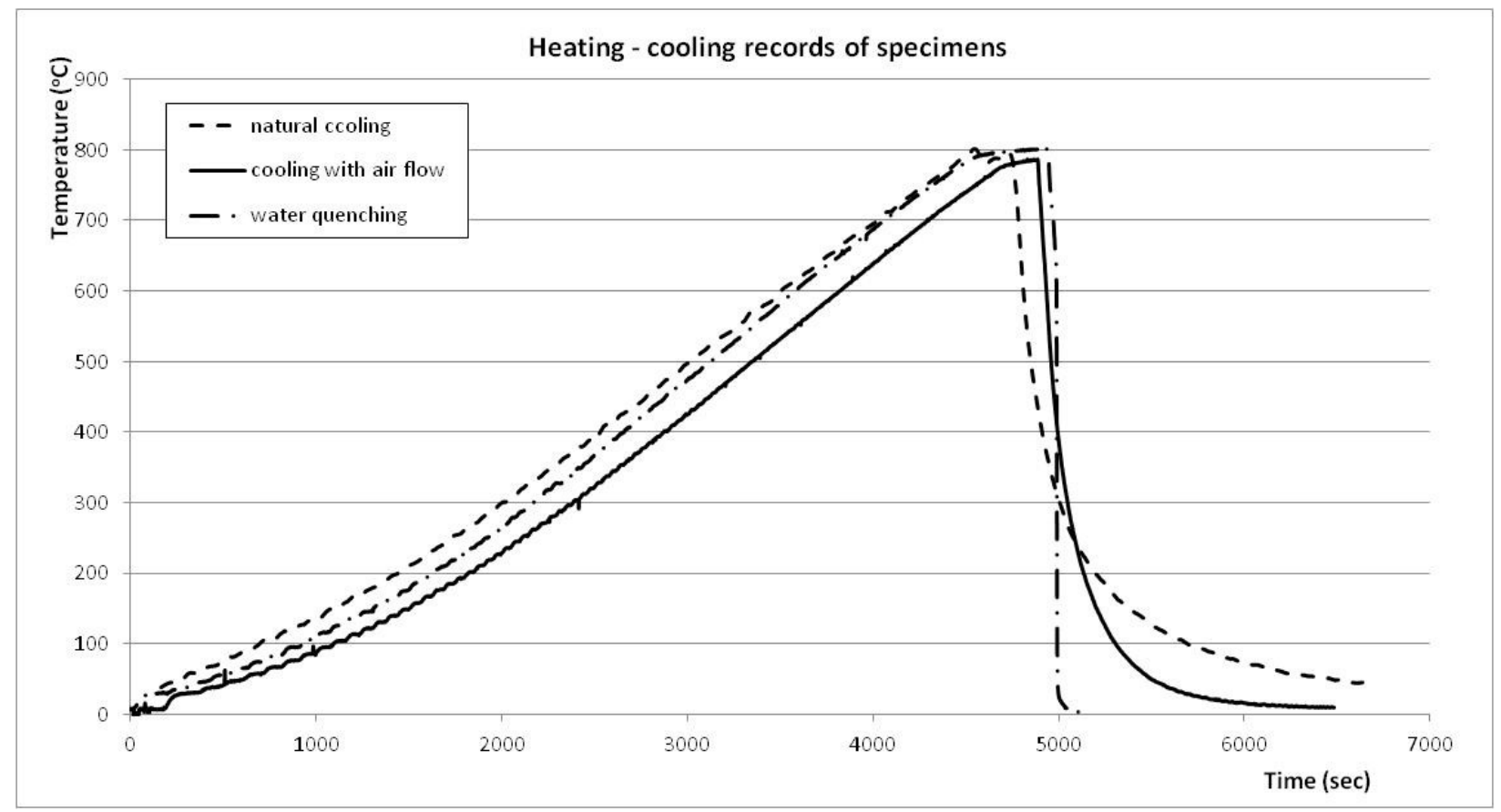

(b)

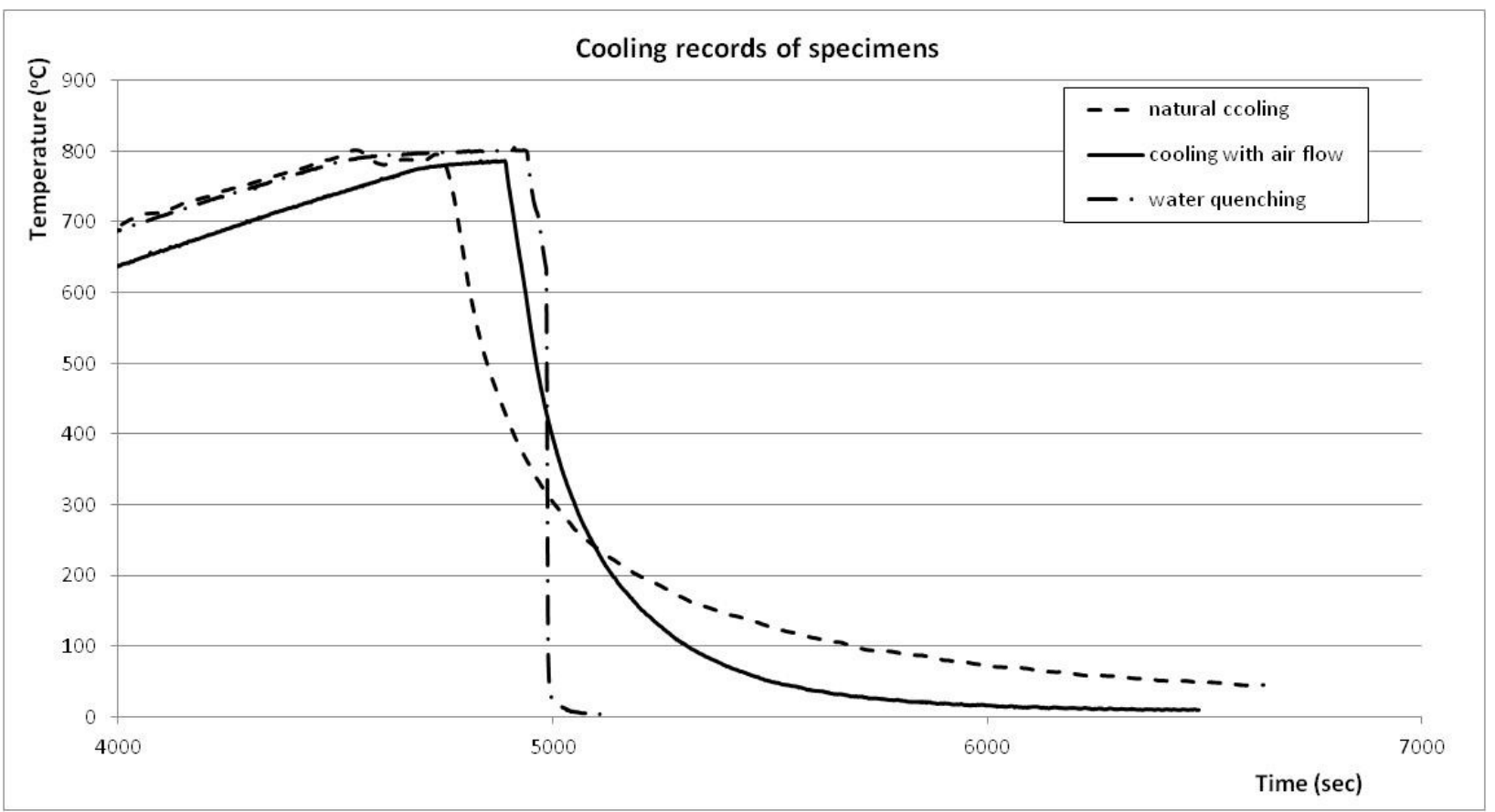

Figure 18. Heating and cooling histories: (a) entire history; (b) enlarged view. 


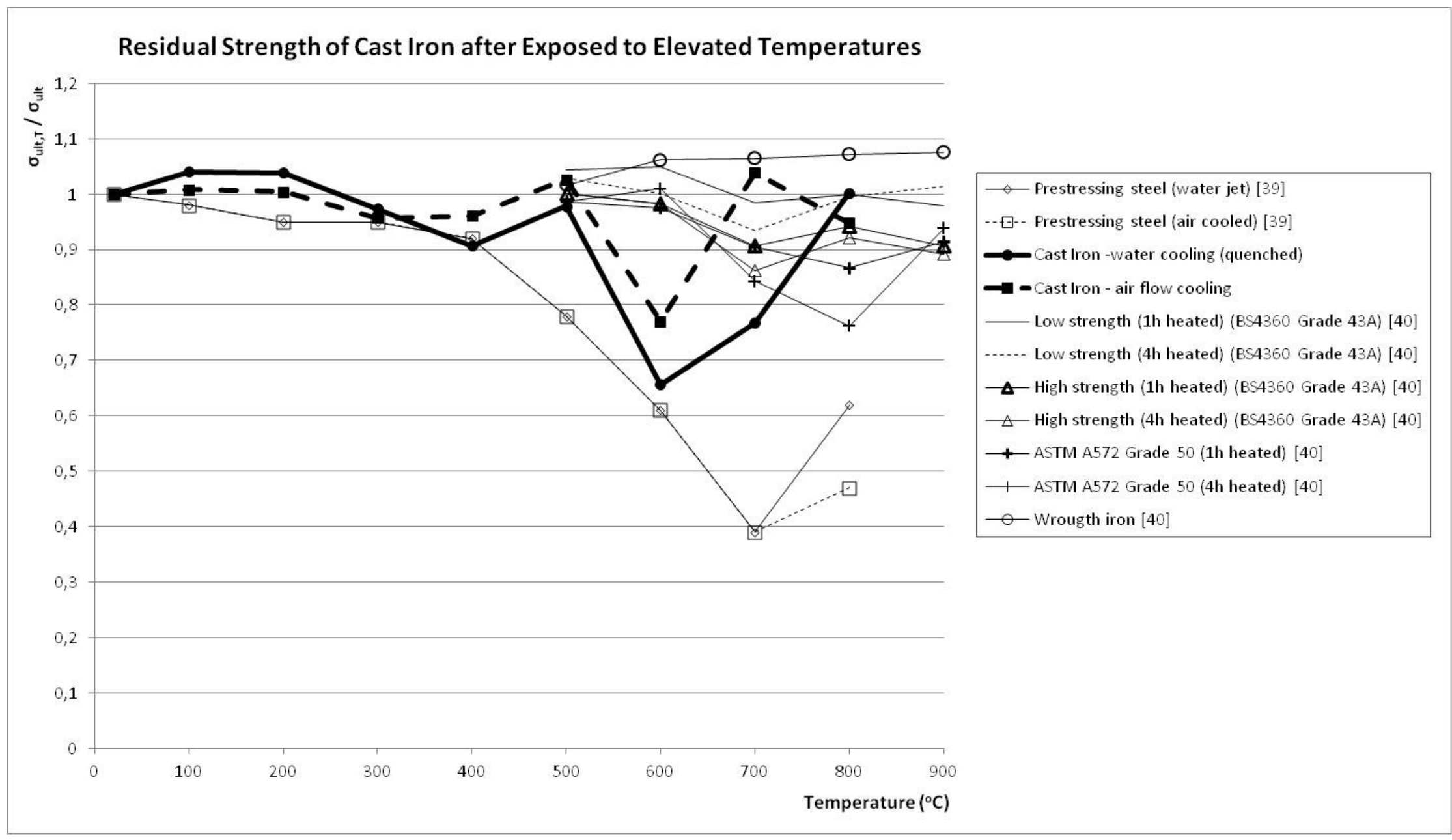

Figure 19. Comparison of residual strength of cast iron after exposure to elevated temperatures with those of wrought iron and structural and prestressing steels. 


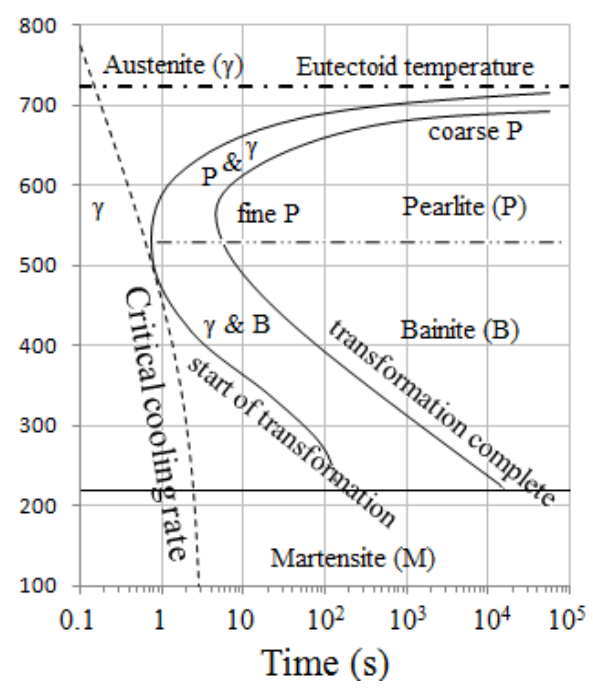

Figure 20: Schematic diagram illustrating isothermal curves (IT), critical cooling curves and resulting microstructures for eutectoid steel [42]

\section{Conclusions}

This paper has presented the results of an extensive set of mechanical test results for cast iron at ambient and elevated temperatures, including tensile and compressive tests, under both steady-state and transient heating conditions, and cooling from high temperatures. Based on analysis of the test results, the mechanical properties of cast iron at elevated temperatures can be determined as follows:

\section{Tensile stress-strain relationship}

The proposed tensile stress strain relationship is bilinear up to $400^{\circ} \mathrm{C}$ and trilinear for higher temperatures. To derive the stress-strain temperature relationship, the following procedure should be applied:

- Determination of the bilinear stress-strain relationship at ambient temperature. This should include the initial linear part until the $0,2 \%$ proof stress and the second part from the $0,2 \%$ proof stress to the ultimate strength/fracture strain.

- At elevated temperatures, the Young's modulus should be reduced according to the EN 1993-1-2 relationship for Young's modulus of steel.

- The 0,2\% proof stress should be reduced according to the EN 1993-1-2 relationship for the yield strength of steel. 
- The ultimate strength should be reduced according to the EN 1993-1-2 relationship for the yield strength of steel. The fracture strain at the ultimate strength should be the same as the failure strain at ambient temperature.

- For temperatures higher that $400^{\circ} \mathrm{C}$, a descending line from the ultimate strength point should be introduced. The stress at the final point is $50 \%$ of the ultimate strength and the final fracture strain is obtained from equation 2.

\section{Compressive stress-strain relationship}

- The proposed compressive stress strain relationship is trilinear. The initial linear relationship until the proportional limit, the second linear part from the proportional limit to the $0,2 \%$ proof stress and then the final line from the $0,2 \%$ proof to the ultimate strength at $10 \%$ strain.

- The proportional limit, the $0,2 \%$ proof stress and the ultimate strength should be reduced based on the ambient temperature values according the EN 1993-1-2 relationship for the yield strength of steel. The strain at the ultimate strength can be conservatively taken as $10 \%$ for all temperatures.

- The Young's modulus should be reduced according the EN 1993-1-2 relationship for Young's modulus reduction of steel.

\section{Coefficient of thermal expansion}

The thermal strain - temperature relationship of cast iron can be assumed to be the same as that of steel in EN 1993-1-2.

\section{Residual strength after cooling}

The limited number of tests of this paper suggest that after cooling to ambient temperature, cast iron regains its strength as structural steel. Its strength is fully recovered at temperatures below $600^{\circ} \mathrm{C}$ and higher than $700^{\circ} \mathrm{C}$. Between these temperatures, the maximum loss of strength is about $20-40 \%$, depending on the cooling method. Taking into account the large safety factors used in design of historic cast iron structures, the results of this research suggest that cast iron structures can be restored after fire damage provided there is no visible damage. 


\section{References}

1. Institution of Structural Engineers (1996), Appraisal of existing structures, Second Edition, The Institution of Structural Engineers, London, UK.

2. Bonson, T. (2000), The first iron-framed building?, Industrial Archaeology Review, Vol. XXII:1, pp 63-66.

3. Falconer, K.A. (1993), Fireproof mills - the widening perspectives, Industrial Archaeology Review, Vol. XVI:1, pp 11-26.

4. Fitzgerald, R. (1998), The development of the cast iron frame in textile mills to 1850 , Industrial Archaeology Review, Vol. X:2, pp 127-145.

5. Friedman, D. (1995), Historical building construction, Norton \& Company Publishers, New York, USA.

6. Gerber, P. (1991), The flax spinning mill in Myslakowice near Jelenia Gora, Poland, Industrial Archaeology Review, Vol. XIII:2, pp 142-151.

7. Hamilton, S.B. (1949), Old cast-iron structures, The Structural Engineer, No 4, pp 173-191.

8. Wouters, I. and Bouw, M. (2006), The development of fireproof construction in Brussels between 1840-1870, Industrial Archaeology Review, Vol. XXVIII:1, pp 17-31.

9. Swailes, T. (2003), 19th century "fireproof' buildings, their strength and robustness, The Structural Engineer, 81(19), 27-34.

10. Silva, T.M.D. and Church, D.G. (2005), Strengthening two London Underground covered ways, Proceedings of the Institution of Civil Engineers - Transport, Vol. 158, Issue TR3, pp 139-147.

11. Friedman, D., Cast-Iron-Column Strength in Renovation Design, Journal of Performance of Constructed Facilities, Vol. 9, No. 3, August 1995, pp. 220-230.

12. Parmenter, M. (1996), An investigation of the strength of cast iron beams, $\mathrm{PhD}$ thesis, Department of Civil and Structural Engineering, UMIST, UK.

13. Rondal, J. and Rasmussen, K.J.R. (2003), On the strength of cast iron columns, Journal of Constructional Steel Research, Vol. 60, p.p. 1257-1270.

14. Brooks, I., Browne, A., Gration, D.A. and McNulty, A. (2008), Refurbishment of St Pancras - justification of cast iron columns, The Structural Engineer, Vol. 3, pp 28-39.

15. Barnfield, J.R. and Porter, A.M. (1984), Historic buildings and fire: fire performance of castiron structural elements, The Structural Engineer, Vol. 62A, Issue 12, pp 373-380.

16. Baxter, A. (1984a), New Concordia Wharf, Fire Engineering aspects, Architects' Journal, Vol. 180, Issue 27, pp 58. 
17. Porter, A. (1998): The behavior of structural cast iron in fire. English Heritage Research Transactions, Vol. 1, pp 11-20.

18. Wouters, I. and Mollaert, M. (2002), Evaluation of the fire resistance of $19^{\text {th }}$ century iron framed buildings, Fire Technology, Vol. 38, pp 383-390.

19. Nieuwmeijer, G.G. (2001). Fire resistance of historic iron structures in multistory buildings. Transactions on the Built Environment, Vol. 55, pp 39-48.

20. Wald, F., and Dagefa, M. (2011), Fire resistance of cast iron columns in Vinohrady Brevery, Application of Structural Fire Engineering, Prague, Czech Republic, pp 443-448.

21. Twilt, I.L. (1999), Fire resistance of cast iron structures in historic buildings, Urban Heritage Building Maintenance, Iron \& Steel, The Netherlands, pp 99-106.

22. Dibb-Fuller, D., Fewtrell, R., and Swift, R. (1998): Windsor Castle: fire behaviour and restoration aspects of historic ironwork, The Structural Engineer, Vol. 76, No 19, pp 367372.

23. Bussell, M.N. and Robinson, M.J. (1998), Investigation, appraisal, and reuse, of a cast-iron structural frame, The Structural Engineer, Vol. 76, Issue 3, pp 37-42.

24. C. Maraveas, Y.C. Wang, T. Swailes, Thermal and mechanical properties of 19th century fireproof flooring systems at elevated temperatures, Construction and Building Materials, Volume 48, November 2013, pp 248-264.

25. Kattus, J.R. and McPerson, B. (1959), Report on properties of cast iron at elevated temperatures, ASTM Special Technical Publication No. 248, Philadelphia, USA.

26. Palmer KB. High temperature properties of cast irons. In Conference on Engineering Performance of Iron Castings; British Cast Iron Research Association; 1970. p. 217-49

27. Donaldson, J.W. (1925), Low-temperature heat treatment of special cast irons, The Foundry Trade Journal, Vol. 31, pp 517-522.

28. Angus TH. Cast Iron: Physical and Engineering Properties. 2nd ed. London-Boston: Butterworths; 1976.

29. Maraveas, C., Wang, Y.C. and Swailes, T., Fire resistance of 19th century fireproof flooring systems: a sensitivity analysis, Construction and Building Materials, Vol. 55, pp 69-81, March 2014.

30. ISO 6892-1:2009: Metallic materials -- Tensile testing -- Part 1: Method of test at room temperature, International Organization for Standardization, 2009, Switzerland.

31. ASTM E9-09: Standard Test Methods of Compression Testing of Metallic Materials at Room Temperature, American Society for Testing and Materials, 2009, USA. 
32. ASTM E209-00: Standard Practice for Compression Tests of Metallic Materials at Elevated Temperatures with Conventional or Rapid Heating Rates and Strain Rates, American Society for Testing and Materials, 2010, USA.

33. Gilbert, G.N.J., An evaluation of the stress/strain properties of flake graphite cast iron in tension and compression, Research Report No. 514, BCIRA Journal of Research and Development, Vol. 7, 1959, pp 745-789.

34. Swailes, T., 19th century cast-iron beams: their design, manufacture and reliability, Proc. Inst. Civ. Engrs, Civ. Engng, 114, 1995, pp 25-35.

35. Kirby B.R., Preston R.R. High temperature properties of hot-rolled, structural steels for use in fire engineering design studies, Fire Safety, 13, 1988, pp 27-37.

36. European Standard EN 1993-1-2: (2005). Eurocode 3 - Design of steel structures - Part 1-2: General rules - Structural fire design. European Committee for Standardization, Brussels, Belgium.

37. ASTM E831-12: Standard Test Method for Linear Thermal Expansion of Solid Materials by Thermomechanical Analysis, American Society for Testing and Materials, 2012, USA.

38. Brannigan, F.L. (2006), Cast iron and steel, Fire Engineering, Vol. 159, pp 126.

39. I. Cabrita Neves, Joao Paulo C. Rodrigues and Antonio de Padua Loureiro, Mechanical properties of reinforcing and prestressing steels after heating, J. Mater. Civ. Eng. 1996.8:189-194.

40. Smith, C.I., Kirby, B.R., Lapwood, D.G., Cole, K.J., Cunningham, A.P. and Preston, R.R. (1981), The reinstatement of fire damaged steel framed structures, Fire Safety Journal, Vol. 4, pp 21-62.

41. Digges, T.G., Rosenberg, S.J. and Geil, G.W. (1966), Heat Treatment and Properties of Iron and Steel, Monograph 88, National Bureau of Standards, Department of Commerce, USA

42. Vander Voort G.F., Atlas of time-temperature diagrams for irons and steels (Materials Data Series), Materials Park, 1991, Ohio.

43. Swailes, T. (2006), Scottish iron structures, Guide for Practitioners, Historic Scotland, Edinburgh, UK. 